\title{
Pluripotency factors regulate the onset of Hox cluster activation in the early embryo
}

Elena Lopez-Jimenez ${ }^{1,}+, \pi$, Julio Sainz de Aja ${ }^{1, \pm, \pi}$, Claudio Badia-Careaga ${ }^{1, \#,}$ Antonio Barral", \#, Isabel Rollan", \#, Raquel Rouco", \#, Elisa Santos ${ }^{11, ~ \#, ~ M a r i ́ a ~ T i a n a ~}{ }^{1,}$ \#, Jesus Victorino1, 2, \#, Hector Sanchez-Iranzo ${ }^{1, ~}$, Rafael D Acemel ${ }^{3}$, Carlos Torroja ${ }^{1}$, Javier Adan ${ }^{1}$, Eduardo Andres-Leon ${ }^{4}$, ", Jose Luis Gomez-Skarmeta ${ }^{3}$, Giovanna Giovinazzo ${ }^{1}$, Fatima Sanchez-Cabo ${ }^{1}$ and Miguel Manzanares ${ }^{1, *}$

${ }^{1}$ Centro Nacional de Investigaciones Cardiovasculares Carlos III (CNIC), 28029 Madrid, Spain.

2 Department of Biochemistry, Faculty of Medicine, Universidad Autónoma de Madrid, Madrid, 28029, Spain.

${ }^{3}$ Centro Andaluz de Biología del Desarrollo (CABD-CSIC/UPO), 41013 Seville, Spain.

${ }^{4}$ Centro Nacional de Investigaciones Oncológicas Carlos III (CNIO), 28029 Madrid, Spain.

† Current address: Department of Surgery and Cancer, Imperial College London.

‡ Current address: Harvard Stem Cell Institute, Cambridge, MA, 02138, USA.

\& Current address: EMBL, 69117 Heidelberg, Germany.

" Current address: Bioinformatics Unit, Instituto de Parasitología y Biomedicina López Neyra (IPBLN-CSIC), 18100 Granada, Spain.

$\pi$ These authors contributed equally and are listed in alphabetical order

\# These authors contributed equally and are listed in alphabetical order

*Corresponding autor (mmanzanares@cnic.es) 


\section{ABSTRACT}

Pluripotent cells are a transient population present in the early mammalian embryo dependent on transcription factors, such as OCT4 and NANOG, which maintain pluripotency while simultaneously suppressing lineage specification. Interestingly, these factors are not exclusive to uncommitted cells, but are also expressed during early phases of differentiation. However, their role in the transition from pluripotency to lineage specification is largely unknown. Using genetic models for controlled Oct4 or Nanog expression during postimplantation stages, we found that pluripotency factors play a dual role in regulating key lineage specifiers, initially repressing their expression and later being required for their proper activation. We show that the HoxB cluster is coordinately regulated in this way by OCT4 binding sites located at the 3' end of the cluster. Our results show that core pluripotency factors are not limited to maintaining the pre-committed epiblast, but are also necessary for the proper deployment of subsequent developmental programs. 


\section{INTRODUCTION}

Pluripotency, the ability of a cell to give raise to derivatives of all embryonic germ layers, occurs in cultured embryonic stem cells and for a brief period during development of the mammalian embryo. A small group of transcription factors, most importantly OCT4, NANOG and SOX2, controls this state both in vivo and in culture by regulating a large battery of downstream target genes $(1,2)$. During preimplantation stages of mammalian embryos, these factors are expressed in the epiblast of the blastocyst, which shares various molecular features with embryonic stem (ES) cells, among them the expression of the core pluripotency factors. It is assumed that progression from pluripotency towards differentiation requires the downregulation of the core pluripotency factors that would lead to the expression of lineage determination genes and turning on of specific developmental pathways. However, the expression of pluripotency factors beyond the blastocyst stage suggests roles not directly related to pluripotency maintenance (3). Oct4 (official gene symbol Pou5f1) is continuously expressed up to embryonic day (E) 8.5 , initially throughout the epiblast and subsequently showing progressive restriction to the posterior part of the embryo $(4,5)$. Nanog is re-expressed at E5.5 but only in the posterior-proximal region where it has been shown to control development of the primordial germ cells $(6,7)$, and is turned off by E7.5 (8). Loss-of-function approaches to investigating the role of Oct4 and Nanog at these stages have proved difficult because preimplantation lethality precludes analysis of later phenotypes $(9$, 10). To overcome early lethality, conditional Oct4 mutants have been analyzed at post-implantation. However, loss of Oct4 at these stages leads to tissue disorganization and proliferation defects at gastrulation, what could obscure potential lineage-specific defects $(11,12)$. Therefore, we still lack a complete understanding of the roles of pluripotency factors during development, as well as how pluripotency and differentiation programs are coordinated in the embryo. 


\section{RESULTS}

\section{Stage-dependent regulation of developmental genes by pluripotency factors}

To overcome the limitations or early embryonic lethality and disruption of gastrulation associated with the loss of function of core pluripotency factors, we used doxycycline (dox)-inducible transgenic mouse models providing controlled Oct4 or Nanog expression in post-implantation embryos (13-15). We chose two different time windows for induction of Oct4 and Nanog: from E4.5 to E7.5 and from E6.5 to E9.5 (Fig. $1 \mathrm{~A}$ ), thus maintaining expression beyond the point when endogenous gene activity is turned off. Robust expression of both transgenes was obtained at E7.5 and E9.5 (Fig. S1A), with higher levels in neural tube and mesoderm (Fig. S1B). Nevertheless, expression levels of Oct4 or Nanog in treated embryos were comparable or even lower to those in E14 or R1 (16) ES cells (Fig. S1C). We analyzed the transcriptomes of embryos from untreated and dox-treated females and compared gene-expression changes between stages and models.

More than $50 \%$ of genes differentially expressed upon Oct4 expression up to E7.5 also changed when Nanog was induced in the same time window (Fig. S1D), and included major developmental regulators. However, this proportion halved when we compared changes occurring in E9.5 embryos (24\%). Similarly, $23 \%$ of genes deregulated by Oct4 at E7.5 also changed at E9.5. As for Nanog, 36\% of genes changing at E7.5 were shared with Oct4, $16 \%$ at E9.5, and only $14 \%$ were common at both stages in Nanog-expressing embryos (Fig. S1D). The observed degree of overlap between changes induced by Oct4 and Nanog may appear small, in light of their many common target genes in embryonic stem (ES) cells (17); however, this finding is in line with the outcome of overexpressing or knocking-down these factors in culture $(18,19)$. Core factors of the pluripotency gene regularly network are known to activate each other's expression $(2,17)$. We observed positive cross-regulation of Oct4 and Nanog at E7.5, but not at E9.5 (Fig. S1A). Furthermore, we did not observe upregulation of other pluripotency factors, such as Sox2, upon Oct4 or Nanog expression. Therefore, there is not an overall activation of the embryonic pluripotency program in the gastrulating embryo driven by these factors. 
We performed unsupervised hierarchical clustering of the data (20) using genes that were differentially expressed in at least one condition (4090 genes). Most of the resulting clusters (Fig. 1B) show a stronger tendency for upregulation or downregulation in only one condition (e.g. clusters \#1-5; Fig. S2A), confirming the largely independent and stage-specific effects of Oct4 and Nanog expression. Functional annotation showed that most clusters were enriched for genes involved in development and transcription, with some exceptions such as cluster \#5, which is enriched for cell-cycle genes, and cluster \#7, which includes genes involved in lipid metabolism (Fig. S2B).

To gain insight into functional targets among the de-regulated genes, we checked for the presence of OCT4 or NANOG binding sites in their vicinity by examining published ChIP-seq data in ES cells $(21,22)$. We assessed for binding near genes from each cluster compared to genes differentially expressed in at least one condition (Fig. 1C). Surprisingly, only three clusters (\#6, \#8 and \#10) showed consistent enrichment for genes located near OCT4 and NANOG sites (Fig. 1C). Moreover, these clusters showed an intriguing pattern in response to Oct4 and Nanog: clusters \#6 and \#10 were upregulated by both Oct4 and Nanog at E7.5 and downregulated at E9.5, whereas cluster \#8 showed the opposite behavior (Fig. S2A). The three clusters are enriched for developmental regulators (Fig. S2B); however, whereas clusters \#6 and \#10 include early epiblast genes (e.g. Chordin, Dnmt3a/3b, Eomes, Eras, Esrrb, Etv5, Fgf4/5, Foxa2, Gsc, Lefty2, Mesp1/2, Nodal, Otx2, Snai1, $T d g f 1$, Zic5), cluster \#8 includes multiple lineage specification genes (e.g. $C d x 1 / 2 / 4$, DIx5/6, Fgf3, Gata5/6, Gbx2, Gli1/2/3, Hnf1b, Hox genes, Irx3/4/5, Meis1/2/3, Msx1/2, Pitx1/2, Tbx genes, and Wnt3a/5a/5b/6) (Fig. 1D).

\section{Widespread regulation of Hox genes by pluripotency factors}

The large number of Hox genes in this last group (18 genes) prompted us to examine the response of all 39 Hox genes to Oct4 and Nanog (Fig. 2A). Nanog has a mild effect on Hox cluster expression (Fig. 2A), mostly downregulating their expression at early stages (14 genes downregulated and 3 upregulated at E7.5, and 5 
upregulated at E9.5). On the other hand, Oct4 has a dramatic effect, significantly downregulating 23 Hox genes when expressed up to E7.5, and upregulating 24 when expressed up to E9.5 (Fig. 2A). It is noteworthy that in this case no Hox gene was upregulated at E7.5 or downregulated at E9.5. Oct4 affects expression of Hox genes from all four clusters (HoxA-D), but excluding most of the posterior Hox genes from paralog groups 10-13. Interestingly, recent work has shown that Oct4 delays the activation of posterior Hox genes in trunk progenitors at later embryonic stages (23), suggesting that Oct4 could have opposite roles in the regulation of anterior and posterior Hox genes during development (24).

These results strongly suggest that endogenous Oct4 might be regulating Hox genes during post-implantation development. To address if Oct4 and Hox genes overlap in the embryo we analyzed published single-cell expression data in E6.5-E7.75 embryos (25) finding that the majority of cells expressing Hox genes co-express Oct4 (Fig. S3A). This does not rule out the possibility that expression of Hox genes is only occurring in cells that might be turning off Oct4, showing low levels of its expression, as a prerequisite for proper lineage commitment. However, Hox expressing cells from E6.5-E7.75 embryos (25) express Oct4 in an equivalent range to that of all Oct4 positive cells from the same stages (Fig. S3B). Together, this evidence is compatible with a direct role of Oct4 in the regulation of Hox clusters.

To determine when the switch from Hox gene repression to activation takes place, we induced Oct4 for 1.5-day periods between E5.5 and E8.0, harvesting embryos between E7.0 and E9.5 (Fig. 2B). We examined the expression of Hoxa1 and three HoxB cluster genes (Hoxb1, Hoxb4 and Hoxb9) by RT-qPCR using genotypematched embryos from non-dox-treated females as controls. Consistent with the transcriptomic data, we observed a switch from repression to activation. However, the switch occurred earlier for Hoxa1 and Hoxb1 than for Hoxb4 and Hoxb9 (Fig. $2 \mathrm{C})$, resembling the collinear activation of the clusters in the early embryo $(26,27)$.

We next examined Oct4-induced changes to HoxB gene expression patterns by in situ hybridization of E7.0-7.5 and E9.5 embryos exposed to dox for 3 days. At E7.07.5, expression of Hoxb1 and Hoxb4 was downregulated in the posterior of the 
embryo, as predicted from the transcriptomic analysis, and at $\mathrm{E} 9.5$ we observed gain of expression for HoxB genes in several domains of the embryo (Fig. 2D). Hoxb1 was the most notably affected, with a shift along the anterior-posterior axis (Fig. S4A, arrowhead) together with upregulation or persistence of expression in presumptive rhombomere 6 territory (Fig. S4A, asterisk). Expression of Hoxb4 conserved its anterior limit of expression (Fig. S4A, arrowhead), but showed an irregular and patchy pattern in the neural tube (Fig. S4A, bracket). As for Hoxb9, the anterior limit of expression in the neural tube (Fig. S4A, white arrowhead) shifted anteriorly in comparison with the anterior limit in the paraxial mesoderm (Fig. S4A, black arrowhead). Most strikingly, all three genes examined showed patches of expression in the anterior neural tube (Fig. 2D and Fig. S4B), a territory normally devoid of Hox expression at all developmental stages (28). In situ hybridization in adjacent sections (fig. S4C) revealed that these patches correspond to Oct4 expressing vesicle-like structures, where the anterior marker Otx2 was lost and Hox genes were expressed in various combinations (Fig. S4D, arrowheads; Fig. S4E, arrows). These results suggest a coordinated response of the HoxB cluster to Oct4, leading to its activation in Hox-free domains such as the forebrain.

On the other hand, Nanog caused no obvious changes in Hox gene expression in E9.5 embryos except for an anterior expansion of the Hoxb1 domain in the neural tube, similar to what we observed for Oct4 (Fig. S4F).

\section{Global control of the HoxB cluster by OCT4}

To investigate how pluripotency factors regulate Hox genes, we examined previously published ChIP-seq binding profiles of OCT4 and NANOG in mouse ES cells (22, 29). We detected almost no binding within the clusters, with the exception of HoxD, but observed prominent peaks at the anterior ends of the clusters (Fig. 3A and Fig. S5A). For example, in the HoxB cluster, both OCT4 and NANOG bind proximally to the Hoxb1 promoter (P-site) and to a distal region (D-site) approximately $9 \mathrm{~kb}$ downstream of the transcriptional start site (Fig. 3A). These sites have been shown to bind OCT4 during ES cell differentiation (30), and are shared sites of OCT4 
binding between ES cells and epiblast-like cells (EpiLC) in the transition from naïve to primed pluripotency (16).

We confirmed these sites were occupied by OCT4 in ES cells by ChIP-qPCR (Fig. 3B), using a region from the Nanog promoter, previously shown to be bound by OCT4 $(29,31)$, as a positive control and other unrelated genomic regions as negative controls (Fig. S5B). ChIP in E9.5 embryos showed no binding, but after dox administration we observed binding at both the P- and D-sites (Fig. 3B), demonstrating that these sites are occupied by OCT4 upon induction of its expression.

The response of multiple Hox genes to Oct4 we observe in the RNAseq dataset and in whole mounts in situs suggests the existence of global mechanisms of Hox cluster regulation by pluripotency factors. To address if these regions could be acting as common regulatory elements for the cluster, we examined their interaction profile by circular chromatin conformation capture followed by high-throughput sequencing (4C-seq) $(32,33)$. We designed viewpoints for both the P-and D-sites and carried out $4 \mathrm{C}$-seq in mouse ES cells, where OCT4 is present and HoxB genes are not expressed, and in dox treated and untreated E9.5 Oct4tg embryos (Fig. 3C). Normalized reads were used to fit a distance decreasing monotone function, to take into account that nearby fragments will randomly interact more frequently, and contacts that deviated significantly from the normal distribution were identified.

The chromatin structure surrounding the anterior end of the HoxB cluster is relatively stable independently of its expression (Fig. $3 \mathrm{C}$ ), as shown for other viewpoints in the cluster (32). Interaction occurs on both sides of the viewpoints: towards the HoxB cluster itself, with a strong limit near Hoxb13; and outside of the cluster towards the telomeric region (Fig. 3C). However, interactions are differently distributed around the viewpoint in ES cells and embryos. In ES cells, there are more interactions towards the Hoxb13 region, possibly reflecting the closed conformation of the cluster mediated by poised promoters (34), whereas in E9.5 embryos interactions increase towards the telomeric gene desert defined by Skap1 (Fig. 3C), whose expression at E7.0-E7.75 is limited to embryonic blood progenitors (25). This difference in 
interactions might reflect the active state of the HoxB cluster in the embryo, where distal regulatory elements located in this region (35) are recruited to define its correct expression, as is also the case for the HoxA cluster (36). Our observations are also in line with recent results that show that the HoxA and HoxD clusters are organized in compact domains in ES cells that open up during differentiation (37). Interestingly, when Oct4 is induced in E9.5 embryos, novel contacts are established from both the $\mathrm{P}$ and $\mathrm{D}$ sites towards the cluster (asterisks, Fig. $3 \mathrm{C}$ ) accompanied by a reduction in the interactions with the Hoxb13 domain (dashed boxes, Fig. 3C). We can conclude that these regions at the telomeric end of the HoxB cluster, which are bound by pluripotency-factors, establish intra-cluster interactions in active or inactive states. Furthermore, the presence of OCT4 in E9.5 embryos leads to a reorganization of the local architecture of the HoxB cluster.

\section{OCT4 is necessary for proper activation of the HoxB cluster}

We next wished to explore the effect of the lack of Oct4 on the expression of Hox genes. To do so, we analyzed expression of HoxB genes in ES cells depleted of Oct4. For this, we used the ZHBTc4 ES cell line that has both copies of endogenous Oct4 deleted and harbors a tetracycline (tet) dependent Oct4 transgene, where addition of the drug leads to the quick downregulation of Oct4 (38). We treated ZHBTc4 ES cells for up to 72 hours (3 days) with tet in $2 \mathrm{i}$ culture conditions (39), in order to minimize differentiation of the cells, leading to complete silencing of Oct4 after the first 24 hours (Fig. S6A). This was accompanied by a more gradual downregulation of Nanog, and a sharp upregulation of $C d \times 2$ as previously described $(38,40)$ after the first day of tet treatment, that declined on following days (Fig. S6A) possibly as the result of selection against partially differentiated cells in $2 \mathrm{i}$ conditions. Genes from the HoxB cluster showed different behaviors in response to loss of Oct4. While Hoxb1 was downregulated in the absence of Oct4 at all days, Hoxb4 showed initial upregulation at day 1 but downregulation by day 3. On the other hand, Hoxb9 was upregulated throughout the 3-day culture (Fig. 4A). Therefore, Oct4 is 
necessary for basal activation of 3' genes, while needed to repress expression of further 5' HoxB genes.

\section{Deletion of the distal OCT4 site disrupts the pattern of HoxB expression during differentiation.}

To complement these observations, we decided to test the necessity of the OCT4 bound regions described above in the regulation of the HoxB cluster by deletion in ES cells by CRISPR/Cas9 mediated genome editing (41). We examined the genomic regions covered by ChIP-seq peaks, finding that the proximal site $(P)$ contains one consensus OCT4 binding site, while the distal site (D) at least two (Fig. S6B). In the case of the $\mathrm{P}$-site, this consensus lies within the previously described proximal Hoxb1 auto-regulatory element (42) and in very close proximity to the promoter. Given the difficulty of deleting this site without compromising other known regulatory inputs on Hoxb1, we decided to only analyze the effect of deleting the D-site. This region does not map to any other known Hoxb1 regulatory elements, such as the two described 3' retinoic acid response elements $(43,44)$ (Fig. S6B).

We generated two independent ES cell clones deleted for the $D$ site (clone \#30 and \#57; Fig. S6B) and analyzed changes in HoxB gene expression during their differentiation towards mesodermal or neural fates (Fig. S6C) $(45,46)$. Comparison of parental with HoxB D-site ${ }^{\Delta / \Delta}$ ES cells along differentiation to mesodermal, hindbrain (with low dose of retinoic acid) or spinal cord (high dose of retinoic acid) showed a similar trend for each of the Hox genes examined independently of the differentiation protocol, and a comparable behavior in the two independent clones (Fig. 4B). Hoxb1 is initially expressed at higher levels in deleted cells, but is downregulated as compared to controls at later stages of differentiation. Hoxb4 also shows initial upregulation, but no significant changes at later time points. Finally, Hoxb9 is consistently activated in deleted cell lines throughout the differentiation window analyzed (Fig. 4B), as also occurs when Oct4 is depleted from ES cells (Fig. $4 A)$. 
To analyze the effect of the deletion in vivo, we used the HoxB D-site ${ }^{\Delta / \Delta} E S$ cells to generate mouse lines. Homozygous mice survive to term, what did not come as a surprise, as deletion of the entire HoxB cluster in homozygosity does not cause embryonic lethality (47). We examined the expression of Hoxb1 and Hoxb4 at E7.5, a time when anterior HoxB genes and Oct4 are still co-expressed (Fig. S3A, B). RTqPCR showed down-regulation of Hoxb1 and upregulation of Hoxb4 in deleted embryos (Fig. 4C). This further confirms the different roles of Oct4 at this stage, when it would be necessary for proper levels of express info Hoxb1 but still lowering Hoxb4.

Whole mount in situ hybridization at the early head-fold stage showed no clear changes in Hoxb1, but an expansion of the expression in the primitive streak region at the posterior part of the embryo of Hoxb4 (white dashed line, Fig. 4D). We also examined expression of HoxB genes in E9.5 embryos from the HoxB D-site ${ }^{\Delta \Delta}$ line, and did not observe mayor changes except for overall lower levels of Hoxb4 expression (Fig. S6D). Therefore, these results suggest that at early stages of expression, OCT4 is necessary to fine-tune expression of HoxB genes in their endogenous domains.

\section{DISCUSSION}

It is generally assumed that pluripotency factors act to restrict lineage decisions before gastrulation. However, Oct4 has been shown to participate in several later developmental decisions, including primitive endoderm development (48), lineage priming $(30,49,50)$, primitive streak proliferation (12), and the regulation of trunk length (23). Furthermore, recent results have shown how the lack of Oct4 in early gastrulating embryos results in a blockade of epithelial-to-mesenchymal transition in the posterior epiblast, thus disrupting proper axis formation (11). Both single-cell RNA-seq data and in situ detection show that Oct4 and Hox genes are co-expressed in cells of the gastrulating embryo, from the onset of Hox gene expression and up to E8.5 $(4,5,25)$. We propose that at these early stages, Oct4 plays a dual role, first 
maintaining Hox genes silent before lineage commitment, and later being required for their proper activation. This behavior is specific for Oct4, as in the case of Nanog we only observe initial repression of Hox genes, which agrees with the recent description of the mutual cross-repression of Nanog and Hoxa1 to differentially regulate a common set of downstream target genes involved in early phases of lineage commitment (51).

The concerted response of Hox genes, together with the chromatin interactions established by bound regions we see in the HoxB cluster, suggests that Oct4 regulates globally Hox clusters and forms part of the complex regulatory apparatus that ensures proper Hox gene expression $(28,36)$. Furthermore, when we examine the expression of anterior, middle and posterior HoxB genes in gain- and loss-offunction models, we observe a collinear response to Oct4, in line with recent findings of the repression of most posterior 5 ' Hox genes by Oct4 $(23,24)$.

Moreover, our expression data indicate that other patterning genes respond in a similar fashion, suggesting that OCT4 and other pluripotency factors mediate a switch from repression to activation of an array of developmental regulators at the time of lineage decisions. Therefore, initial lineage specification involves not only dismantling of the core pluripotency gene regulatory network (3), but also a switch in function of key factors such as OCT4 from repressors to activators that would supervise the transition from pluripotency to lineage determination. 


\section{MATERIALS AND METHODS}

\section{Animal models}

Double-homozygote transgenic males of the Oct4/rtTA (R26-M2rtTA;Col1a1-tetOOct4) (14) or Nanog/rtTA (R26-M2rtTA;Col1a1-tetO-Nanog) (15) mouse lines were mated with CD1 females, which were treated with 0.2 or $1 \mathrm{mg} / \mathrm{ml}$ dox in the drinking water to induce the Oct4 or Nanog transgene respectively in embryos. For Oct4 transgene induction in E7.5 embryos to be used for in situ hybridazation, a single $100 \mu \mathrm{l}$ intraperitoneal injection of $25 \mu \mathrm{g} / \mu \mathrm{l}$ doxycycline was administered to pregnant females at E5.5, followed by $0.5 \mathrm{mg} / \mathrm{ml}$ dox administration in drinking water. Non treated mice of the same genotype were used as controls. Mouse lines deleted for the Oct4 distal site adjacent to Hoxb1 were generated by blastocyst injection of mutated ES cells (see below) following standard procedures (52).

\section{RNA-seq}

RNA-seq was performed with three biological replicates, each consisting of pools of 8-12 E7.5 embryos or three E9.5 embryos obtained from untreated (controls) or doxycycline-treated double heterozygous embryos. Equally, three biological replicates of E14 ES cells were used for RNA-seq. Single-end sequencing was performed by the CNIC Genomics Unit using a GAllx sequencer. Adapters were removed with Cutadapt v1.14 and sequences were mapped and quantified using RSEM v1.2.20 to the transcriptome set from Mouse Genome Reference NCBIM37 and Ensembl Gene Build version 67. Differentially expressed genes between groups were identified using the limma bioconductor package. Only p-values $<0.05$ adjusted through Benjamini-Hochberg procedure were considered as significant. Clustering analysis was conducted for all genes differentially expressed between the induced and control conditions for any of the four conditions. Overrepresented biological categories were identified using DAVID v6.8 (53). Lists of genes located close to OCT4 and NANOG binding sites were generated from published ChIP-seq datasets $(21,22)$. 
Single-cell gene expression data from Scialdone et al. (2016) was analyzed to assess co-expression of Oct4 and Hox gene. A gene is considered to be expressed in a cell when its expression level is > 0 FPM (fragments per million).

\section{RT-qPCR assays}

Total RNA from single embryos from E8.0 onwards, embryo pools up to E7.5, or ES cells directly lysed in their wells, was extracted with RNeasy kit (Qiagen) and digested with DNAse I (Qiagen) to remove genomic DNA. 0.5-1.0 $\mu \mathrm{g}$ of total RNA was reverse transcribed using Quantitech Reverse kit (Applied Biosystems). Quantitative PCR was performed with SYBR green Master Mix (Applied Biosystems) on an $A B$ 7900-Fast-384 machine. Expression values were normalized to the expression of Actb and Ywhaz (whose expression as measured in our RNA-seq data did not change upon Oct4 or Nanog induction) using the comparative $C_{T}$ method (54) and standard deviations were calculated and plotted using Prism 7.0 software (GraphPad). All assays were performed in triplicate.

\section{In situ hybridization}

In situ hybridization in whole mount embryos or sections was performed using digoxigenin-labeled probes as described (55). Probes for Hoxb1, Hoxb4, Hoxb9 and Otx2 were generated by PCR, and the probe for Oct 4 was kindly provided by Tristan Rodriguez (Imperial College London). Early embryos were staged according to Forlani et al (2003).

\section{C-seq}

4C was performed as previously described $(32,33)$ on two replicates of pools of 60 70 E9.5 embryos or $1-2 \times 10^{6}$ G4 ES cells. Samples were crosslinked with $2 \%$ PFA, frozen in liquid nitrogen and stored at $-80^{\circ}$. Chromatin was digested with Dpnll (New England BioLabs) followed by Nlalll (New England BioLabs), and ligated with T4 DNA Ligase (Promega). For all experiments, $0.5-1 \mu \mathrm{g}$ of the resulting $4 \mathrm{C}$ template 
was used for the subsequent PCR. 4C libraries were sequenced (single-end) at the CNIC Genomics Unit using an Illumina HiSeq 2500 sequencer. Sequences were mapped and quantified using RSEM v1.2.20 to the Mouse Genome Reference NCBIM37. Reads located in fragments flanked by two restriction sites of the same enzyme, in fragments smaller than $40 \mathrm{bp}$ or within a window of $10 \mathrm{~kb}$ around the viewpoint were filtered out. Mapped reads were converted to reads per first enzyme fragment ends and smoothed using a 30-fragment mean running window algorithm. Smoothed scores from each experiment were then normalized to the total number or reads before the visualization. To calculate the frequency of captured sites per window Fastq files were demultiplexed using Cutadapt with the view point sequences as indexes. Potential Illumina adaptor contaminants and small chimeric reads were removed. Processed reads were assigned to their corresponding genomic fragment after a virtual digestion of the reference genome with the first and second restriction enzymes. Reads located in fragments $5 \mathrm{~kb}$ around the viewpoint were filtered out. Quantification was performed considering each fragment end as one capture site if one or more sequences were mapped to it. The number of capture sites was summarized per 30 fragments window. The frequency of capture sites per window was used to fit a distance decreasing monotone function and Z-scores were calculated from its residuals using a modified version of FourCSeq (56). Significant contacts were considered in cases where the $z$-score was $>2$ in both replicates and deviated significantly (adjusted $p$ value $<0.05$ ) from its normal cumulative distribution in at least one of the replicates.

\section{Chromatin immunoprecipitation}

Chromatin immunoprecipitation (ChIP) was performed using 109.5 embryos or $1 \mathrm{x}$ $10^{6} \mathrm{ES}$ cells per experiment. After recovery, embryos were treated with Collagenase Type I (Stemcell technologies; 07902) at $0,125 \%$ for $1 \mathrm{~h}$ at $37^{\circ}$. Then, embryos were desegregated using a pipette and washed with cold PBS. Samples were fixed and protein-DNA complexes cross-linked by treatment with 1\% formaldehyde (Pierce, 289069) for 15 min rocking at RT. To stop fixation, glycine (Nzytech, MBO1401)) 
was added to a final concentration of $125 \mathrm{mM}$ during $10 \mathrm{~min}$. Next, ChIP was performed using the ChIP-T High Sensitivity kit (Active motif; 53040), following manufacturer's instructions. DNA was sheared into fragments ranging from $200 \mathrm{bp}$ to 1000 bp using a sonicator (Diagenode Bioruptor Water Bath Sonicator, 30 seconds ON 30 seconds OFF for 30 minutes). Immunoprecipitations was carried out using rabbit polyclonal anti-OCT4 antibody (Abcam; ab19857), and anti-Rabbit IgG polyclonal antibody (Abcam; ab171870) was used as negative control. Enrichment was measured by qPCR. A fragment from the Nanog promoter was used as a positive control $(29,31)$, and genomic fragments from the loci of Anks $1 b$, Smg 6 and Tiam1 as negative controls (57), after checking they did not contain OCT4 bound peaks (29).

\section{ES culture, cell editing and differentiation}

ZHBTc4 cells were maintained in culture on $0.1 \%$ gelatin (sigma) using corning p24 plates with cell bind surface. Medium contained inactivated fetal calf serum (Hyclon), LIF (produced in-house) and 2i (PD0325901 and CHIR99021 Sigma). After one day in culture cells were treated with $1 \mathrm{ug} / \mathrm{ml}$ tetracycline (Sigma) to turn of Oct4. Cells were collected from day 1 to 3 from the start of treatment. CRISPR/Cas9-mediated deletions in G4 mouse ES cells were generated using two guide RNAs together with a plasmid for Cas9. Cells were transfected, selected by sorting, and replated.

G4 ES cells (control), clone \#30 and clone \#57 were differentiated as described (45, 46) in monolayer using corning p24 plates with cell bind surface and with $0.1 \%$ gelatin (Sigma) added 30 min before passing. Cells were grown in N2B27 media supplemented with $10 \mathrm{ng} / \mathrm{ml} \mathrm{bFgf}(R \& D)$ for 3 days (d1-d3) and then were transferred into different media depending on the differentiation process. To induce hindbrain identity 10 nM RA (Sigma) was added from D3-D5. Spinal cord identity was induced by the addition of $5 \mu \mathrm{M}$ CHIR99021 (Sigma) from D2 to D3 followed by 100 nM RA from D3-D5. To induce mesodermal differentiation the cells were treated with CHIR990215uM from D2-D5. Cells were collected at each time point by adding lysis buffer directly to the wells. 


\section{SUPPLEMENTARY MATERIAL}

Fig. S1. Characterization of the Octt ${ }^{\text {tg }}$ or Nanog ${ }^{\text {tg }}$ mouse models.

Fig. S2. Transcriptomic analysis of changes induced by Oct4 and Nanog expression in the mouse embryo.

Fig. S3. Co-expression of Oct4 and Hox genes in the early postimplantation embryo.

Fig. S4. Changes to Hox gene expression patterns by pluripotency factors.

Fig. S5. Binding of OCT4 to mouse Hox clusters.

Fig. S6. Characterization of Oct4 depleted, and OCT4 D-site deleted ES cells and embryos.

Table S1. Differentially expressed genes upon doxycycline treatment of Oct $4^{\text {tg }}$ or Nanog ${ }^{\text {tg }}$ inducible models in E4.5 to E7.5 and E6.5 to E9.5 time windows.

Table S2. Clusters generated by unsupervised hierarchical clustering of genes differentially expressed in at least one condition.

Table S3. Gene Ontology analysis of clusters generated by unsupervised hierarchical clustering of genes differentially expressed in at least one condition.

Table S4. Primers and oligonucleotides used in this study. 


\section{ACKNOWLEDGEMENTS}

We wish to thank Beatriz Fernandez-Tresguerres for initial input to this work; Manuel Serrano and Konrad Hochedlinger for the Nanog ${ }^{\text {tg }}$ mouse line; Austin Smith for the ZHBTc4 ES cell line; Tristan Rodriguez for reagents and discussions; Teresa Rayon, Miguel Torres and Moisés Mallo for comments and suggestions; Juan J. Tena for advice; the CNIC Genomics and Transgenesis Units for assistance; Simon Bartlett for English editing; and members of Manzanares lab for continued support. This work was supported by the Spanish government (grants BFU2014-54608-P and BFU2017-84914-P to MM; BFU2016-74961-P and BFU2016-81887-REDT to JLGS), the Andalusian Government (grant BIO-396 to JLGS) and the European Research Council (ERC) under the European Union's Horizon 2020 research and innovation program (grant agreement No 740041 to JLGS). RR and RDA held FPU fellowships from the Spanish Ministry of Education, Culture and Sports (MECD). JV is a recipient of a "La Caixa" Fellowship and a Graduate Fellow of the Madrid City Council) at the Residencia de Estudiantes. Work in the lab of JLGS is supported by a María de Maetzu Unit of Excellence Grant (MDM-2016-0687) to the Department of Gene Regulation and Morphogenesis of the CABD. The CNIC is supported by the Spanish Ministry of Science, Innovation and Universities and the Pro CNIC Foundation, and is a Severo Ochoa Center of Excellence (SEV-2015-0505). 


\section{REFERENCES}

1. Chambers I \& Tomlinson SR (2009) The transcriptional foundation of pluripotency. Development 136(14):2311-2322.

2. Nichols J \& Smith A (2012) Pluripotency in the embryo and in culture. Cold Spring Harb Perspect Biol 4(8):a008128.

3. Osorno R, et al. (2012) The developmental dismantling of pluripotency is reversed by ectopic Oct4 expression. Development 139(13):2288-2298.

4. Downs KM (2008) Systematic localization of Oct-3/4 to the gastrulating mouse conceptus suggests manifold roles in mammalian development. Dev Dyn 237(2):464475.

5. Yeom $\mathrm{Yl}$, et al. (1996) Germline regulatory element of Oct-4 specific for the totipotent cycle of embryonal cells. Development 122(3):881-894.

6. Chambers I, et al. (2007) Nanog safeguards pluripotency and mediates germline development. Nature 450(7173):1230-1234.

7. Zhang M, et al. (2018) Esrrb Complementation Rescues Development of Nanog-Null Germ Cells. Cell Rep 22(2):332-339.

8. Hart AH, Hartley L, Ibrahim M, \& Robb L (2004) Identification, cloning and expression analysis of the pluripotency promoting Nanog genes in mouse and human. Dev Dyn 230(1):187-198.

9. Mitsui K, et al. (2003) The homeoprotein Nanog is required for maintenance of pluripotency in mouse epiblast and ES cells. Cell 113(5):631-642.

10. Nichols J, et al. (1998) Formation of pluripotent stem cells in the mammalian embryo depends on the POU transcription factor Oct4. Cell 95(3):379-391.

11. Mulas C, et al. (2018) Oct4 regulates the embryonic axis and coordinates exit from pluripotency and germ layer specification in the mouse embryo. Development 145(12).

12. DeVeale $B$, et al. (2013) Oct4 is required $\sim E 7.5$ for proliferation in the primitive streak. PLoS genetics 9(11):e1003957.

13. Economou C, et al. (2015) Intrinsic factors and the embryonic environment influence the formation of extragonadal teratomas during gestation. BMC Dev Biol 15:35. 
14. Hochedlinger K, Yamada Y, Beard C, \& Jaenisch R (2005) Ectopic expression of Oct4 blocks progenitor-cell differentiation and causes dysplasia in epithelial tissues. Cell 121(3):465-477.

15. Piazzolla D, et al. (2014) Lineage-restricted function of the pluripotency factor NANOG in stratified epithelia. Nature communications 5:4226.

16. Buecker C, et al. (2014) Reorganization of enhancer patterns in transition from naive to primed pluripotency. Cell Stem Cell 14(6):838-853.

17. Loh YH, et al. (2006) The Oct4 and Nanog transcription network regulates pluripotency in mouse embryonic stem cells. Nat Genet 38(4):431-440.

18. Nishiyama A, et al. (2013) Systematic repression of transcription factors reveals limited patterns of gene expression changes in ES cells. Scientific reports 3:1390.

19. Correa-Cerro LS, et al. (2011) Generation of mouse ES cell lines engineered for the forced induction of transcription factors. Scientific reports 1:167.

20. Sturn A, Quackenbush J, \& Trajanoski Z (2002) Genesis: cluster analysis of microarray data. Bioinformatics 18(1):207-208.

21. Chen X, et al. (2008) Integration of external signaling pathways with the core transcriptional network in embryonic stem cells. Cell 133(6):1106-1117.

22. Marson A, et al. (2008) Connecting microRNA genes to the core transcriptional regulatory circuitry of embryonic stem cells. Cell 134(3):521-533.

23. Aires R, et al. (2016) Oct4 is a Key Regulator of Vertebrate Trunk Length Diversity. Dev Cell 38(3):262-274.

24. Mallo M (2018) Reassessing the Role of Hox Genes during Vertebrate Development and Evolution. Trends Genet 34(3):209-217.

25. Scialdone A, et al. (2016) Resolving early mesoderm diversification through single-cell expression profiling. Nature 535(7611):289-293.

26. Kmita M \& Duboule D (2003) Organizing axes in time and space; 25 years of colinear tinkering. Science 301(5631):331-333.

27. Deschamps J \& van Nes J (2005) Developmental regulation of the Hox genes during axial morphogenesis in the mouse. Development 132(13):2931-2942. 
28. Alexander T, Nolte C, \& Krumlauf R (2009) Hox genes and segmentation of the hindbrain and axial skeleton. Annu Rev Cell Dev Biol 25:431-456.

29. Whyte WA, et al. (2013) Master transcription factors and mediator establish superenhancers at key cell identity genes. Cell 153(2):307-319.

30. Simandi Z, et al. (2016) OCT4 Acts as an Integrator of Pluripotency and SignalInduced Differentiation. Mol Cell 63(4):647-661.

31. Rodda DJ, et al. (2005) Transcriptional regulation of nanog by OCT4 and SOX2. J Biol Chem 280(26):24731-24737.

32. Noordermeer D, et al. (2014) Temporal dynamics and developmental memory of 3D chromatin architecture at Hox gene loci. Elife 3:e02557.

33. van de Werken $\mathrm{HJ}$, et al. (2012) Robust 4C-seq data analysis to screen for regulatory DNA interactions. Nat Methods 9(10):969-972.

34. Barbieri M, et al. (2017) Active and poised promoter states drive folding of the extended HoxB locus in mouse embryonic stem cells. Nature structural \& molecular biology 24(6):515-524.

35. Nolte C, Jinks T, Wang X, Martinez Pastor MT, \& Krumlauf R (2013) Shadow enhancers flanking the HoxB cluster direct dynamic Hox expression in early heart and endoderm development. Dev Biol 383(1):158-173.

36. Neijts R, et al. (2016) Polarized regulatory landscape and Wnt responsiveness underlie Hox activation in embryos. Genes Dev 30(17):1937-1942.

37. Kundu S, et al. (2017) Polycomb Repressive Complex 1 Generates Discrete Compacted Domains that Change during Differentiation. Mol Cell 65(3):432-446 e435.

38. Niwa H, Miyazaki J, \& Smith AG (2000) Quantitative expression of Oct-3/4 defines differentiation, dedifferentiation or self-renewal of ES cells. Nat Genet 24(4):372-376.

39. Ying QL, et al. (2008) The ground state of embryonic stem cell self-renewal. Nature 453(7194):519-523.

40. Niwa $\mathrm{H}$, et al. (2005) Interaction between Oct3/4 and Cdx2 determines trophectoderm differentiation. Cell 123(5):917-929.

41. Ran FA, et al. (2013) Genome engineering using the CRISPR-Cas9 system. Nat Protoc 8(11):2281-2308. 
42. Popperl H, et al. (1995) Segmental expression of Hoxb-1 is controlled by a highly conserved autoregulatory loop dependent upon exd/pbx. Cell 81(7):1031-1042.

43. Marshall $\mathrm{H}$, et al. (1994) A conserved retinoic acid response element required for early expression of the homeobox gene Hoxb-1. Nature 370(6490):567-571.

44. Langston AW, Thompson JR, \& Gudas LJ (1997) Retinoic acid-responsive enhancers located $3^{\prime}$ of the Hox A and Hox B homeobox gene clusters. Functional analysis. J Biol Chem 272(4):2167-2175.

45. Gouti M, et al. (2017) A Gene Regulatory Network Balances Neural and Mesoderm Specification during Vertebrate Trunk Development. Dev Cell 41(3):243-261 e247.

46. Gouti $\mathrm{M}$, et al. (2014) In vitro generation of neuromesodermal progenitors reveals distinct roles for wnt signalling in the specification of spinal cord and paraxial mesoderm identity. PLoS Biol 12(8):e1001937.

47. Medina-Martinez O, Bradley A, \& Ramirez-Solis R (2000) A large targeted deletion of Hoxb1-Hoxb9 produces a series of single-segment anterior homeotic transformations. Dev Biol 222(1):71-83.

48. Frum T, et al. (2013) Oct4 cell-autonomously promotes primitive endoderm development in the mouse blastocyst. Dev Cell 25(6):610-622.

49. Le Bin GC, et al. (2014) Oct4 is required for lineage priming in the developing inner cell mass of the mouse blastocyst. Development 141(5):1001-1010.

50. Radzisheuskaya A, et al. (2013) A defined Oct4 level governs cell state transitions of pluripotency entry and differentiation into all embryonic lineages. Nat Cell Biol 15(6):579-590.

51. De Kumar B, et al. (2017) Dynamic regulation of Nanog and stem cell-signaling pathways by Hoxa1 during early neuro-ectodermal differentiation of ES cells. Proc Natl Acad Sci U S A 114(23):5838-5845.

52. Nagy A, Gertsensten M, Vintersten K, \& Behringer R (2003) Manipulating the mouse embryo: a laboratory manual (Cold Spring Harbor Laboratory Press, Cold Spring Harbor, New York) 3rd Ed.

53. Huang da W, Sherman BT, \& Lempicki RA (2009) Systematic and integrative analysis of large gene lists using DAVID bioinformatics resources. Nat Protoc 4(1):44-57. 
54. Schmittgen TD \& Livak KJ (2008) Analyzing real-time PCR data by the comparative C(T) method. Nat Protoc 3(6):1101-1108.

55. Ariza-McNaughton L \& Krumlauf R (2002) Non-radioactive in situ hybridization: simplified procedures for use in whole-mounts of mouse and chick embryos. Int Rev Neurobiol 47:239-250.

56. Klein FA, et al. (2015) FourCSeq: analysis of 4C sequencing data. Bioinformatics 31(19):3085-3091.

57. Handoko L, et al. (2011) CTCF-mediated functional chromatin interactome in pluripotent cells. Nat Genet 43(7):630-638.

58. Shen $\mathrm{Y}$, et al. (2012) A map of the cis-regulatory sequences in the mouse genome. Nature 488(7409):116-120. 
bioRxiv preprint doi: https://doi.org/10.1101/564658; this version posted March 5,2019 . The copyright holder for this preprint (which was not certified by peer review) is the author/funder, who has granted bioRxiv a license to display the preprint in perpetuity. It is made available under aCC-BY-NC 4.0 International license.

Dual regulation of Hox genes by pluripotency factors

Lopez-Jimenez et al.

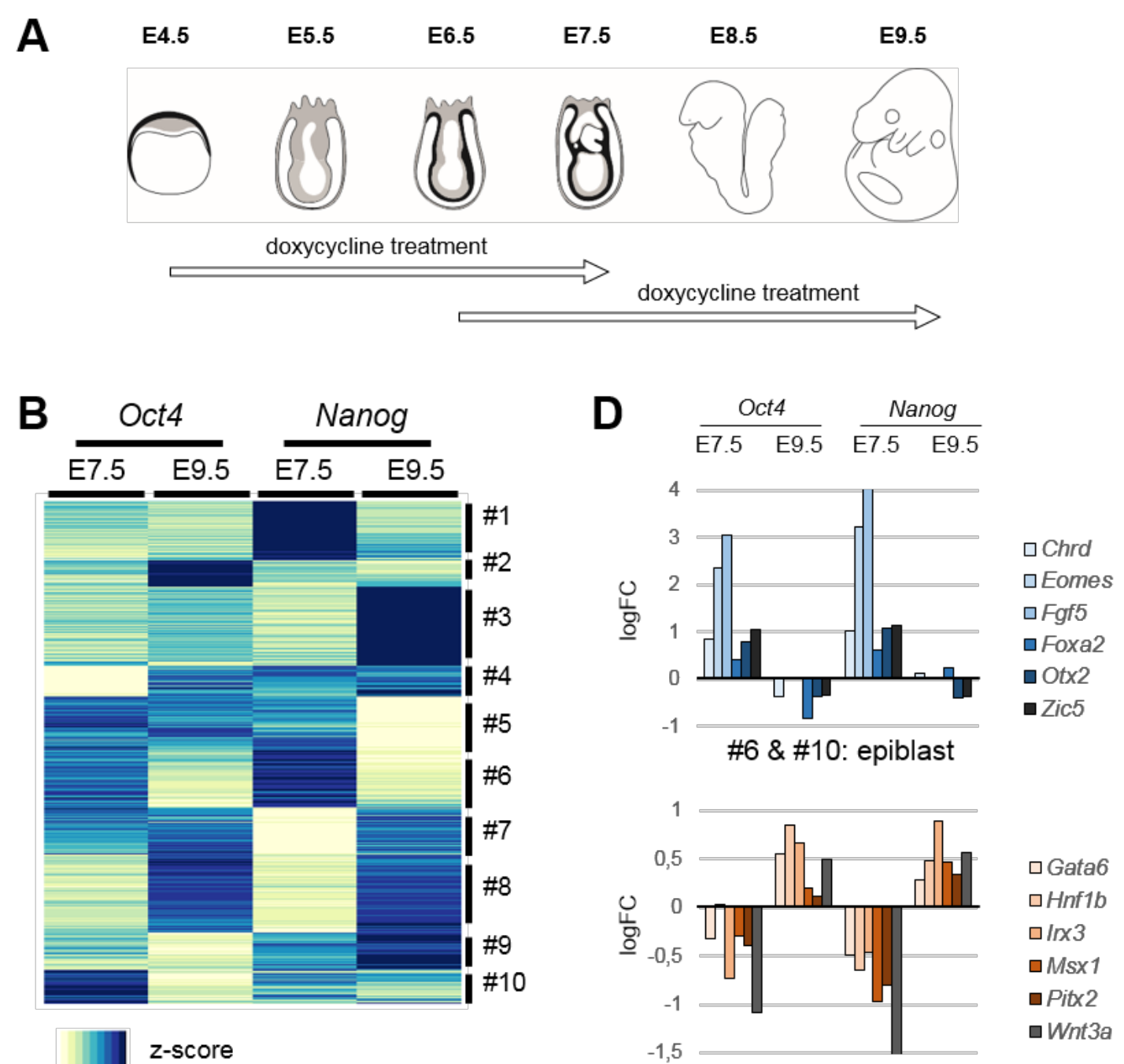

$\begin{array}{lll}-1.5 & 0 & 1.5\end{array}$

\#8: lineage specifiers

C

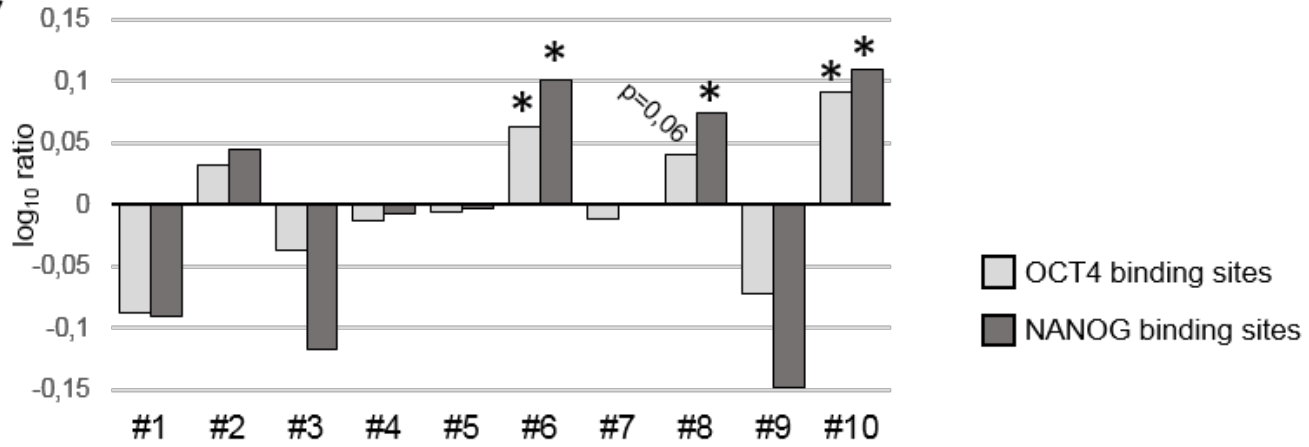


Fig. 1. Oct4 and Nanog coordinate developmental programs in the post-gastrulation mouse embryo. (A) Diagram showing the windows of doxycycline treatment used to induce Oct4 or Nanog expression at post-implantation stages of mouse development. (B) Gene expression changes driven by expression of Oct4 or Nanog for 3 days up to E7.5 or E9.5; unsupervised hierarchical clustering of genes differentially expressed in at least one condition segregated genes into 10 groups according to behavior (clusters \#1-\#10). (C) Enrichment in genes located in the vicinity of ChIP-seq-defined OCT4 or NANOG binding sites, shown as the $\log _{10}$ ratio of each cluster versus genes differentially expressed in at least one of the conditions analyzed. Two-tailed Student $t$-test; + , adjusted $P$ value $<0.05$; ${ }^{*}$, adjusted $P$ value $<0.01$. (D) Representative examples of developmental genes showing opposite behaviors in response to Oct4 and Nanog; genes are either early epiblast markers that are upregulated early and downregulated late (clusters \#6 and \#10; top panel) or later lineage specifiers that are downregulated early and upregulated late (cluster \#8; bottom panel). Expression differences between dox-treated and untreated embryos are shown as logFC of CPMs (counts per million) from RNA-seq data. 
bioRxiv preprint doi: https://doi.org/10.1101/564658; this version posted March 5, 2019. The copyright holder for this preprint (which was not certified by peer review) is the author/funder, who has granted bioRxiv a license to display the preprint in perpetuity. It is made available under aCC-BY-NC 4.0 International license.

Dual regulation of Hox genes by pluripotency factors Lopez-Jimenez et al.

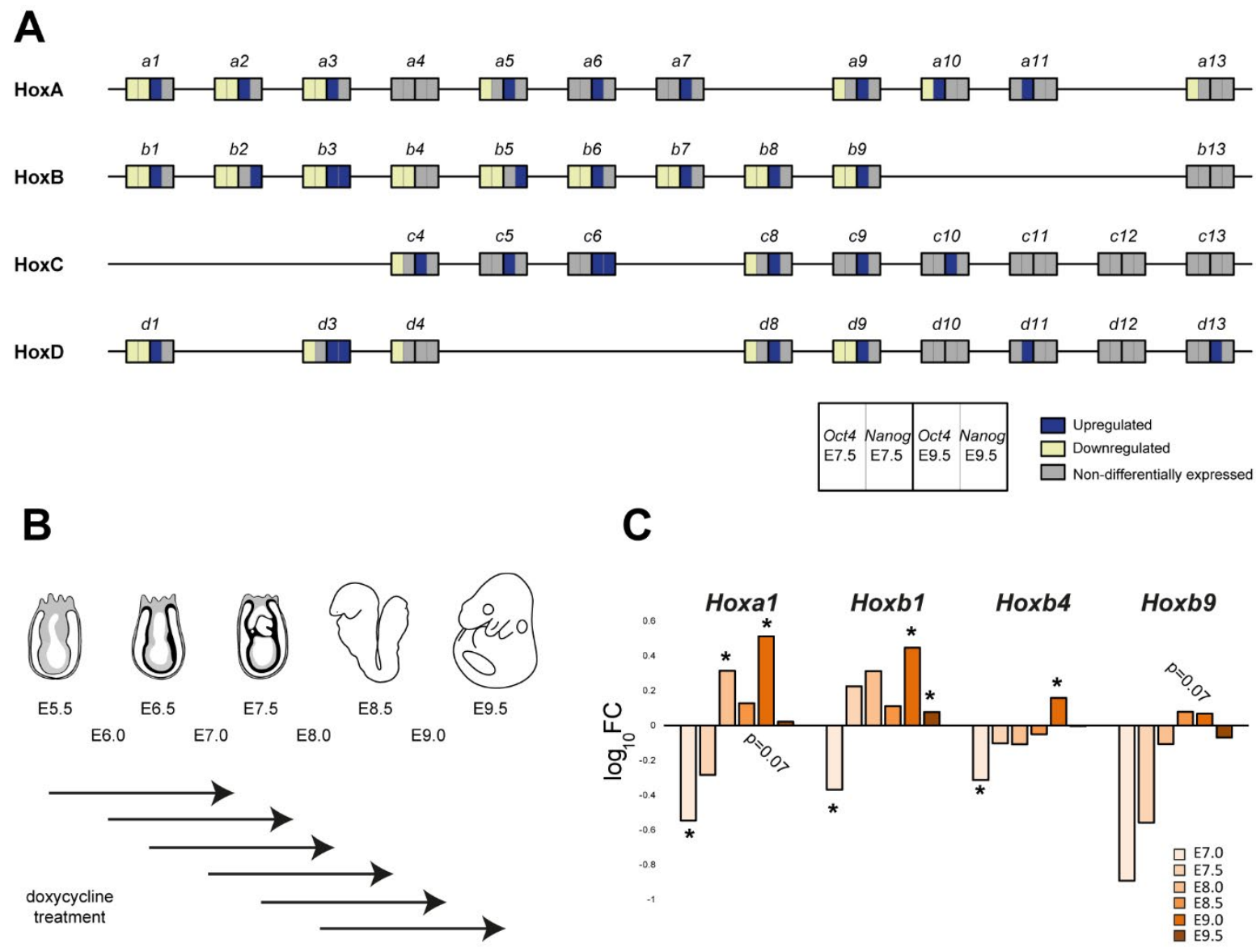

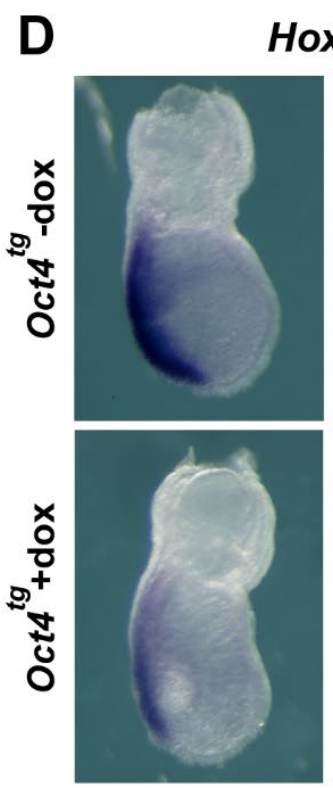

E7.0-7.5

\section{$x b 1$}
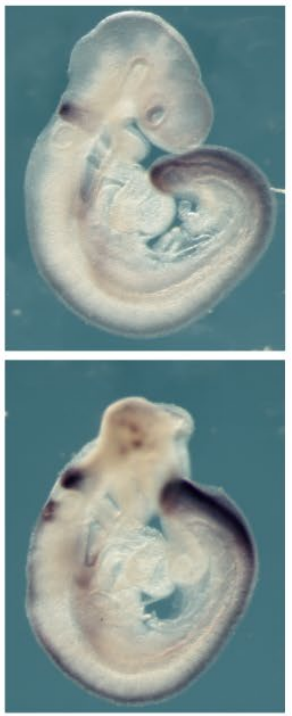

E9.5

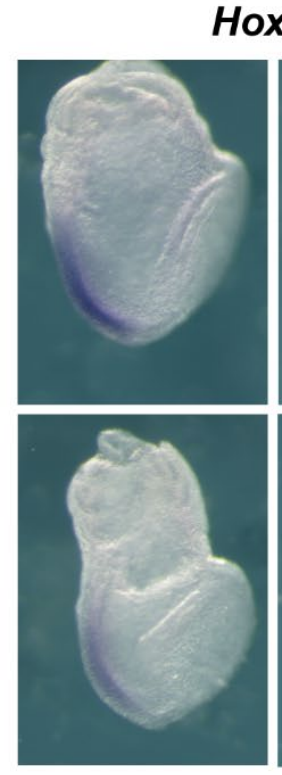

E7.5
Hoxb4
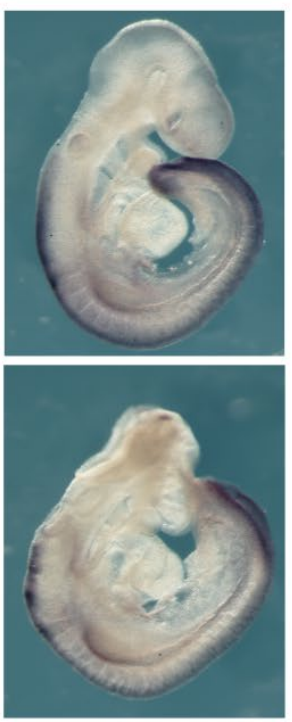

E9.5
Hoxb9
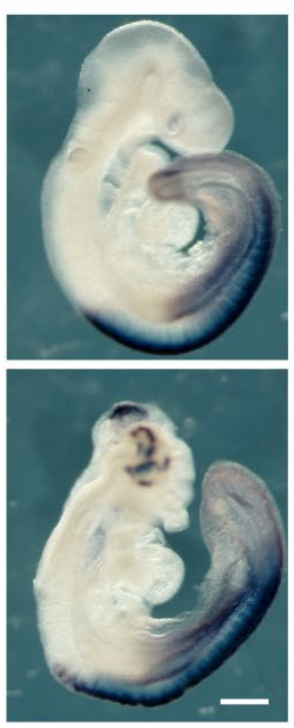

E9.5 
Fig. 2. Pluripotency factors mediate a global switch from Hox gene repression to activation. (A) Hox cluster gene expression changes induced by Oct4 or Nanog at E7.5 or E9.5, as identified in the RNA-seq analysis. Yellow, downregulated; blue, upregulated; grey, unchanged. $(B)$ Diagram depicting the nested windows of 1.5 day dox treatment for Oct4 induction between E5.5 and E9.5. (C) Changes in the expression of selected Hox genes (Hoxa1, Hoxb1, Hoxb4 and Hoxb9) induced by Oct4 during development, shown as log ratios of RT-qPCR-measured relative RNA levels in untreated and dox-treated embryos as in $\mathrm{B} ;{ }^{*} P$ value $<0.05$ by two-tailed Student $t$-test. $(D)$ In situ hybridization analysis of HoxB cluster gene expression in E7.5 and E9.5 untreated (control, top row) and dox-treated (bottom row) Oct4tg embryos. Scale bar, $140 \mu \mathrm{m}$ (E7.0-7.5), $170 \mu \mathrm{m}$ (E7.5), $380 \mu \mathrm{m}$ (E9.5). 
bioRxiv preprint doi: https://doi.org/10.1101/564658; this version posted March 5,2019 . The copyright holder for this preprint (which was not certified by peer review) is the author/funder, who has granted bioRxiv a license to display the preprint in perpetuity. It is made available under aCC-BY-NC 4.0 International license.

Dual regulation of Hox genes by pluripotency factors

Lopez-Jimenez et al.

A

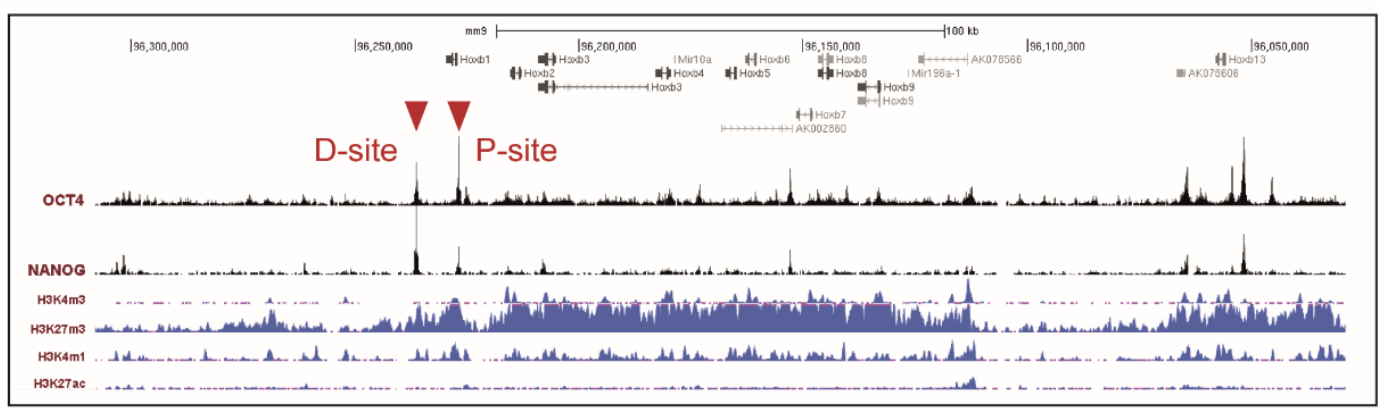

B
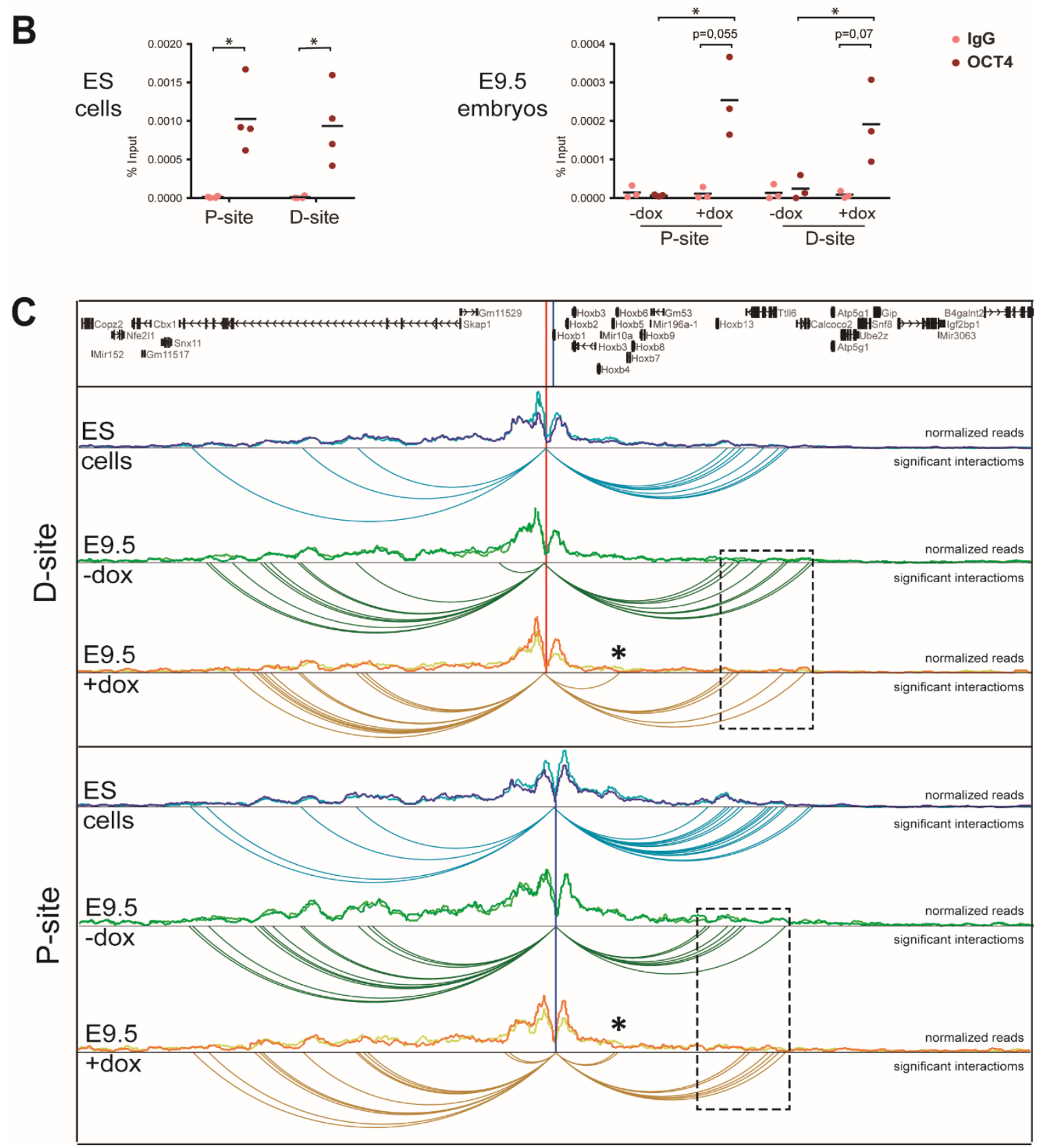
Fig. 3. Pluripotency factor binding sites establish long-distance contacts in the HoxB cluster. (A) ChIP-seq binding profiles for OCT4 and NANOG (29) along the HoxB cluster (mm9; chr11:96,029,042-96,307,981; reversed). Distribution of histone marks for active transcription (H3K4m3), repression $(\mathrm{H} 3 \mathrm{~K} 27 \mathrm{~m} 3)$ and active regulatory elements (H3K4m1, H3K27ac) in Bruce4 ES cells (58) is shown below. Red arrowheads indicate two strong binding sites neighboring Hoxb1 at the anterior end of the cluster. $(B)$ ChIP-qPCR of OCT4 binding to the P-and D-sites in ES cells (left panel, $\mathrm{n}=4$ ) and in untreated (-dox) and treated (+dox) E9.5 Oct4tg embryos (right panel, $\mathrm{n}=3$ ). Enrichment is shown as percentage of input for $\lg \mathrm{G}$ (negative control) and anti-OCT4 antibody. Horizontal bars indicate means. ${ }^{*} P$ value $<0.05$ by two-tailed Student $t$-test. (C) Chromatin interaction profile established from viewpoints located at the $\mathrm{P}$ - and $\mathrm{D}$-sites in a $1 \mathrm{Mb}$ window surrounding the HoxB cluster (mm9; chr11:95,725,993-96,725,993) in ES cells, and untreated (-dox) and treated (+dox) E9.5 Oct4tg embryos. Distribution of normalized reads in two replicates each is shown, and below significant interactions. Asterisks indicate novel intra-cluster interactions established in dox treated embryos, and boxed regions (dashed line) the interactions established towards the Hoxb13 region. 
bioRxiv preprint doi: https://doi.org/10.1101/564658; this version posted March 5, 2019. The copyright holder for this preprint (which was not certified by peer review) is the author/funder, who has granted bioRxiv a license to display the preprint in perpetuity. It is made available under aCC-BY-NC 4.0 International license.

Dual regulation of Hox genes by pluripotency factors

Lopez-Jimenez et al.

A

ZHBTc4 ES cells

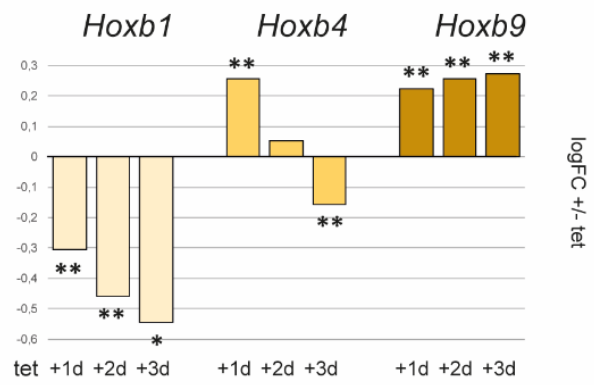

B
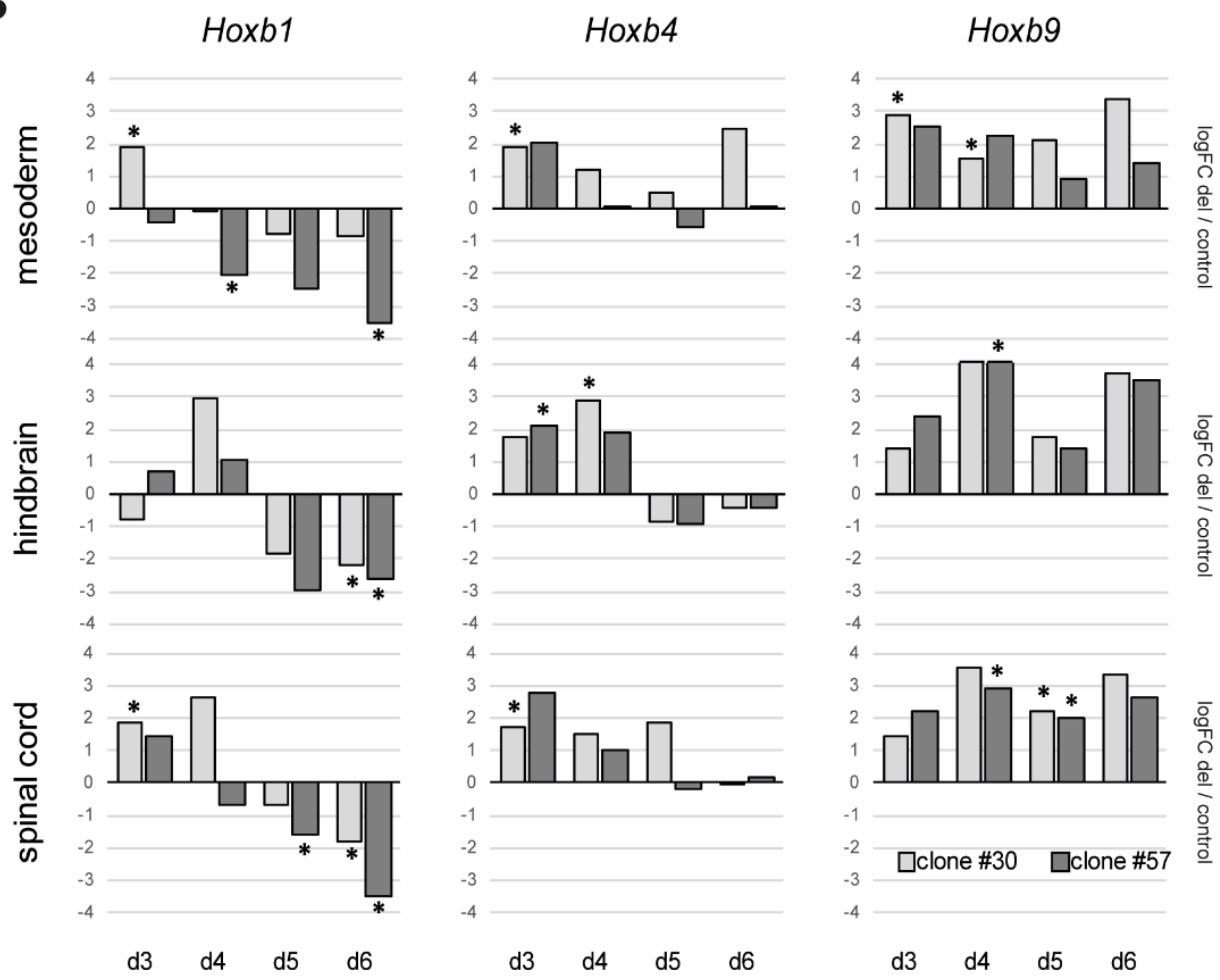

C
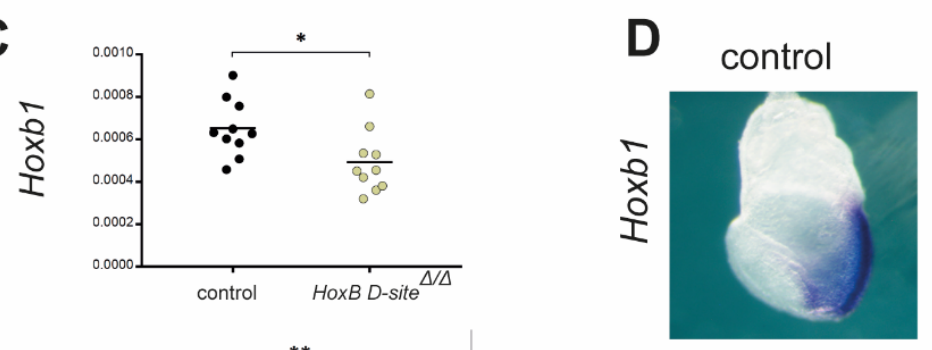

HoxB D-site ${ }^{\Delta / \Delta}$
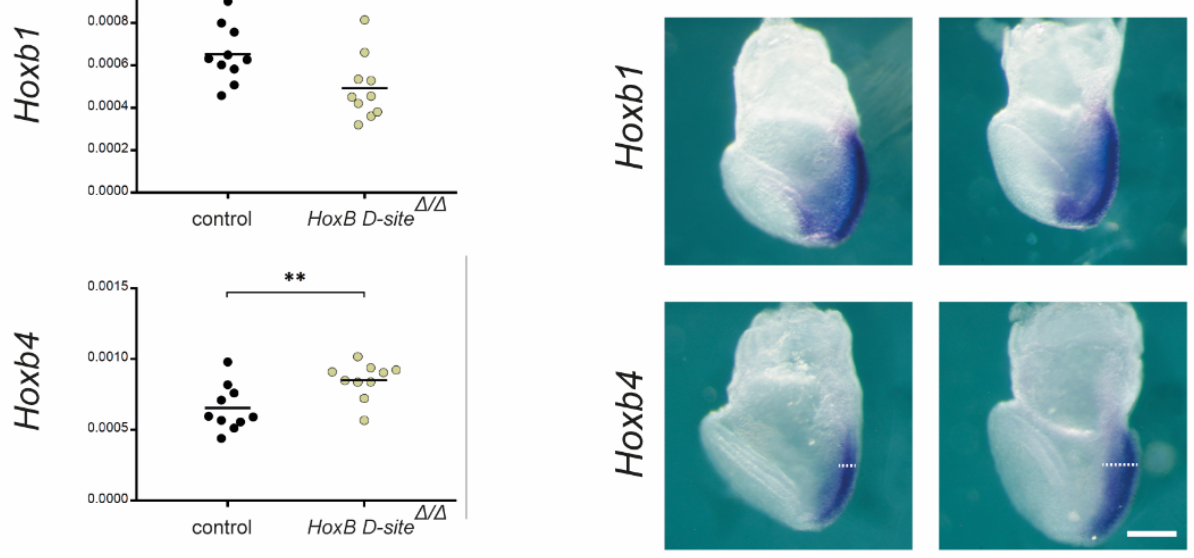
Fig 4. OCT4 is required for correct expression of HoxB genes during differentiation. (A) Changes in the expression of Hoxb1, Hoxb4 and Hoxb9 in ES cells upon Oct4 depletion. Differences in expression are shown as log-fold-change of RT-qPCRmeasured relative RNA levels measured by RT-qPCR in ZHBTc4 ES cells treated with tetracycline for three days (d1-d3) versus untreated cells. Statistical significance was calculated by Fisher's Least Significant Difference test; $\mathrm{n}=3 ; P$ value: ${ }^{*}<0.05$, ** <0.01. (B) Changes in the expression of Hoxb1, Hoxb4 and Hoxb9 as a consequence of the deletion of the distal OCT4 binding site up to six days of differentiation (d3-d6) of ES cells to mesoderm, hindbrain, or spinal cord lineages. Differences in expression are shown as log-fold-change of RT-qPCR-measured relative RNA levels in two independent deleted homozygous clones (\#30, light gray; \#57, dark gray) versus control ES cells. $\mathrm{n}=3$; * $P$ value $<0.05$ by two-tailed Student $t$-test. (C) Expression of Hoxb1 and Hoxb4 in E7.5 control (blue) and HoxBD-site ${ }^{\Delta / \Delta}$ (pale yellow) embryos as quantified by RT-qPCR. $\mathrm{n}=10$; $P$ value: ${ }^{*}<0.05,{ }^{* *}<0.01$ by two-tailed Student $t$-test. (D) Expression of Hoxb1 (top) and Hoxb4 (bottom) in E7.5 early headfold stage HoxB $D$-site ${ }^{\Delta / \Delta}$ (right) embryos compared to controls (left); $\mathrm{n}=6$. Dashed lines indicate the extension of Hoxb4 expression in the posterior region of the embryo. Scale bar, $200 \mu \mathrm{m}$. 
bioRxiv preprint doi: https://doi.org/10.1101/564658; this version posted March 5, 2019. The copyright holder for this preprint (which was not certified by peer review) is the author/funder, who has granted bioRxiv a license to display the preprint in perpetuity. It is made available under aCC-BY-NC 4.0 International license.

Dual regulation of Hox genes by pluripotency factors

Lopez-Jimenez et al.

A
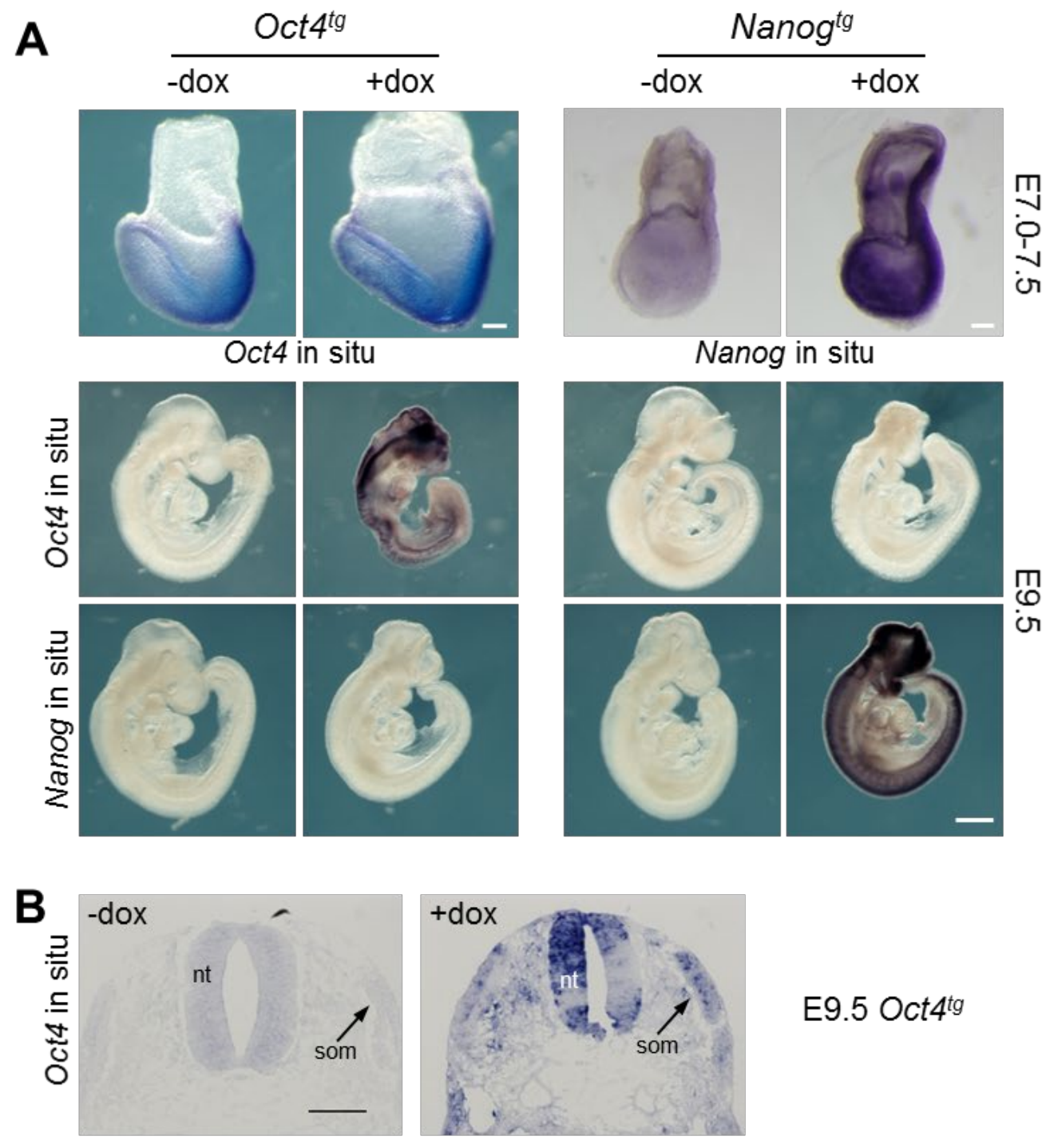

\section{E9.5 Oct4tg}

C
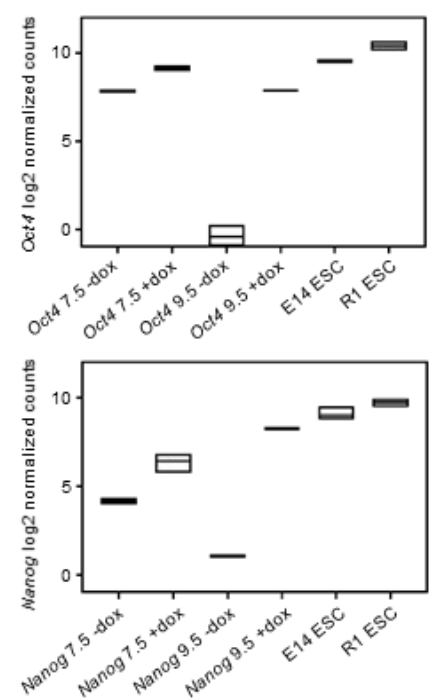

D
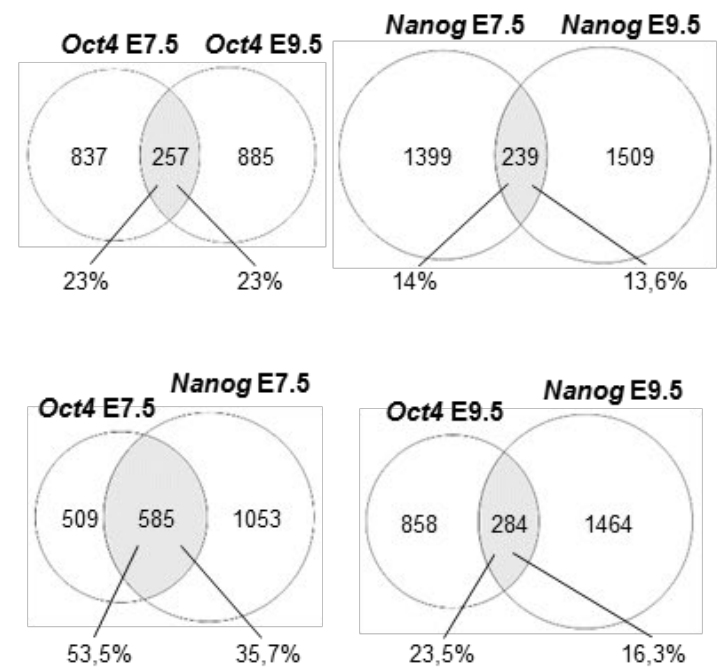
Fig. S1. Characterization of the Oct $4^{t g}$ or Nanog ${ }^{t g}$ mouse models. (A) Expression of Oct4 and Nanog as determined by whole mount in situ hybridization in E7.0-7.5 and E95 untreated (controls, -dox) and treated (+dox) embryos from both transgenic lines. At E9.5, these factors do not cross-regulate. Scale bars, $100 \mu \mathrm{m}$ (E7.0-7.5), $500 \mu \mathrm{m}(\mathrm{E} 9.5)(B)$ In situ hybridization on sections of E9.5 untreated (controls, -dox) and treated (+dox) Oct4tg embryos showing induced Oct4 expression in the neural tube (nt) and somites (som). Scale bar, $100 \mu \mathrm{m}$. (C) Comparison of the expression levels of Oct4 and Nanog between Oct4tg or Nanog ${ }^{\text {tg }}$ E7.5 and E9.5 embryos, without or with dox, and two strains of ES cells (E14 and R1), as log2 of normalized CPMs (counts per million) from RNA-seq data. $(D)$ Overlap between genes differentially expressed in the Oct4tg or Nanog ${ }^{\text {tg }}$ mouse models upon dox treatment in two 3-day time windows (up to E7.5 and up to E9.5). 
bioRxiv preprint doi: https:/doi.org/10.1101/564658; this version posted March 5,2019 . The copyright holder for this preprint (which was not certified by peer review) is the author/funder, who has granted bioRxiv a license to display the preprint in perpetuity. It is made available under aCC-BY-NC 4.0 International license.

Dual regulation of Hox genes by pluripotency factors

Lopez-Jimenez et al.

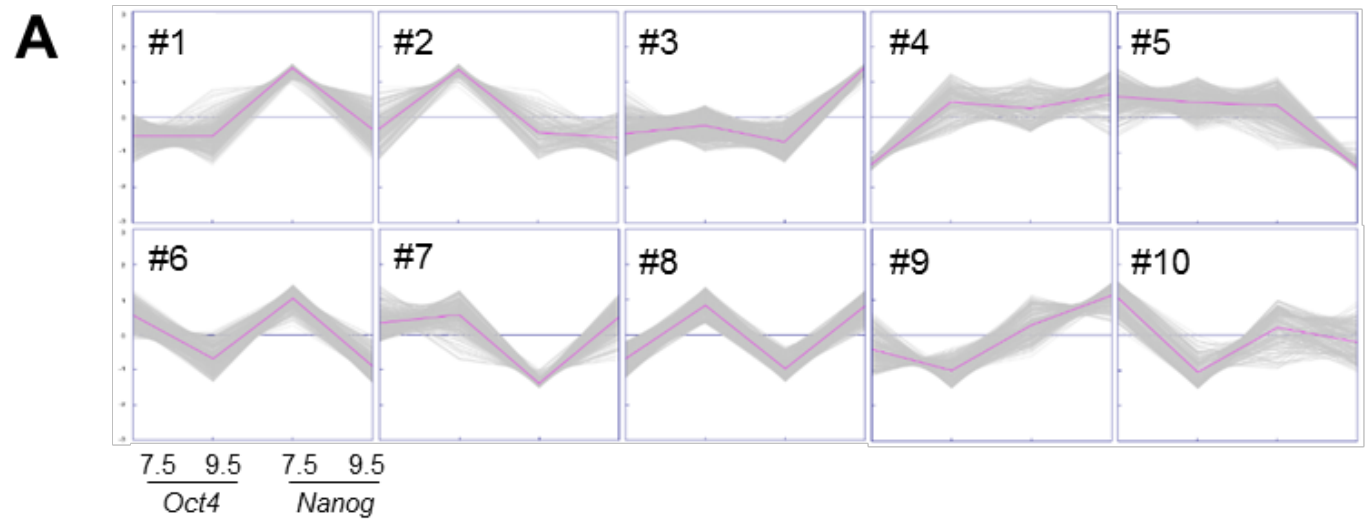

B

female pregnancy

aging

positive regulation of fibroblast. positive regulation of angiogenesis

transcription, DNA-templated

cell-cell adhesion

angiogenesis

cell adhesion

Notch signaling pathway

multicellular organism development

cell cycle

protein folding

cell division

nervous system development

positive regulation of transcription from.

embryonic limb morphogenesis

positive regulation of gene expression

neural tube closure

multicellular organism development anterior/posterior pattern specification positive regulation of transcription from.

heart development

multicellular organism development

nervous system development negative regulation of transcription.

regulation of transcription, DNA-.

$\begin{array}{lllllllllll}0 & 1 & 2 & 3 & 4 & 5 & 6 & 7 & 8 & 9 & 10\end{array}$

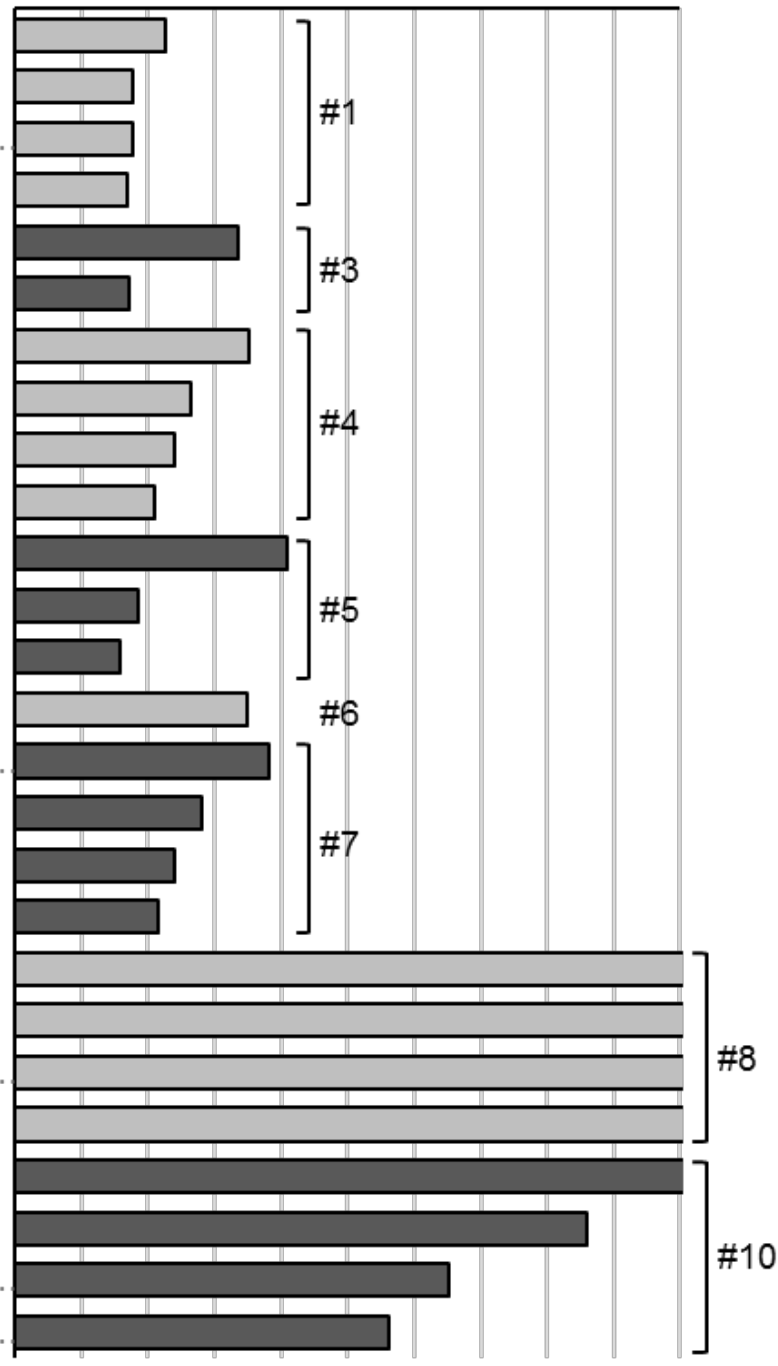

- $\log 10$ (adj pvalue) 
Fig. S2. Transcriptomic analysis of changes induced by Oct4 and Nanog expression in the mouse embryo. $(A)$ Grouping of differentially expressed genes by k-means clustering, showing the response to Oct4 or Nanog expression in the two time windows analyzed; y axis, z-scores. $(B)$ Enriched categories for each cluster with a $P$ value $<0.05$ (Bonferroni adjustment). Clusters \#2 and \#9 do not show significant enrichment for any category. Selected categories are shown; full listings are provided in Dataset S3. 
A

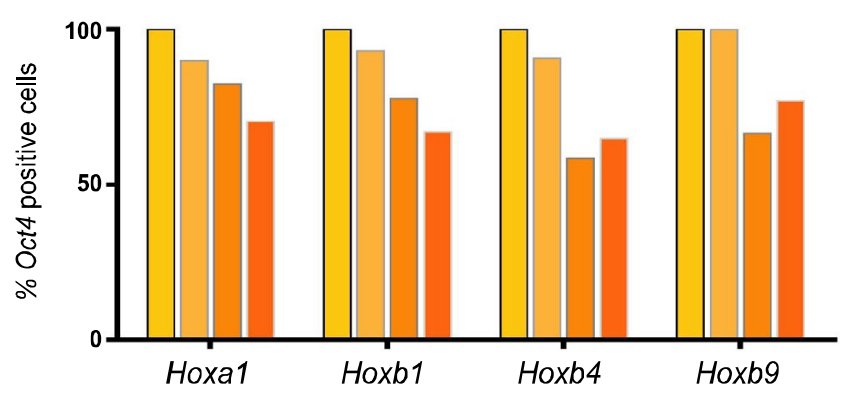

B
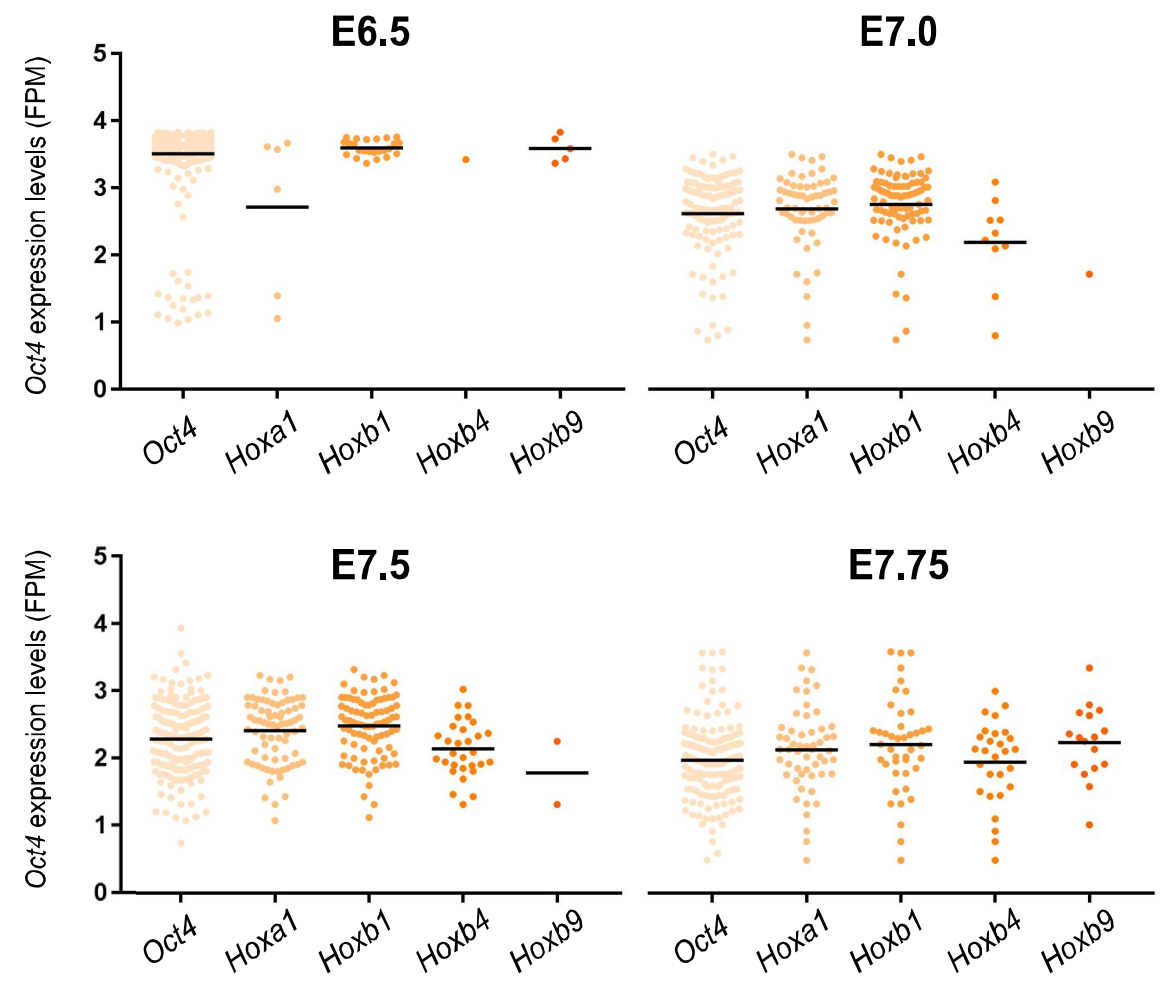

E7.75

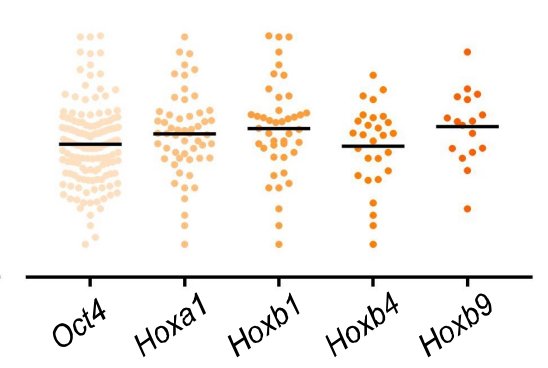

Fig. S3. Co-expression of Oct4 and Hox genes in the early postimplantation embryo. (A) Percentage of single cells expressing Hoxa1, Hoxb1, Hoxb4 and Hoxb9 at E6.5E7.75 that also express Oct4. $(B)$ Expression levels of Oct4 in single cells coexpressing Hox genes at E6.5-E7.75, as log10 of FPM values; the rightmost column from each graph shows the expression levels of Oct4 in all positive cells at that stage. Horizontal black bars indicate mean values. Single cell RNA-seq data from early embryos was obtained from Scialdone et al. 2016. 
bioRxiv preprint doi: https://doi.org/10.1101/564658; this version posted March 5, 2019. The copyright holder for this preprint (which was not certified by peer review) is the author/funder, who has granted bioRxiv a license to display the preprint in perpetuity. It is made available under aCC-BY-NC 4.0 International license.

Dual regulation of Hox genes by pluripotency factors

Lopez-Jimenez et al.

A

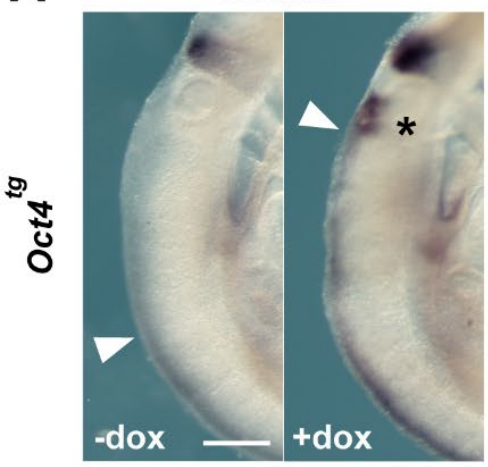

Hoxb4

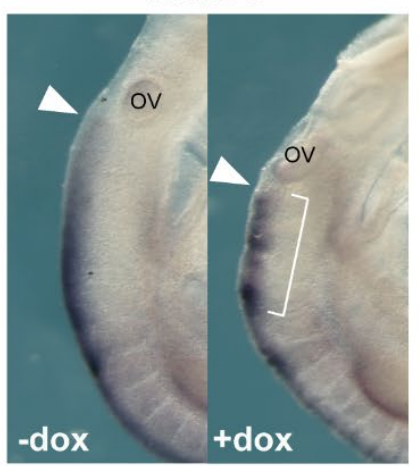

\section{Hoxb9}

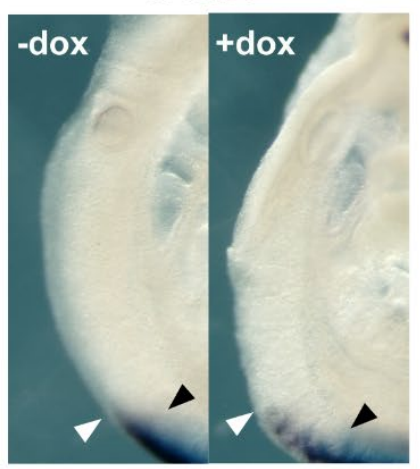

D
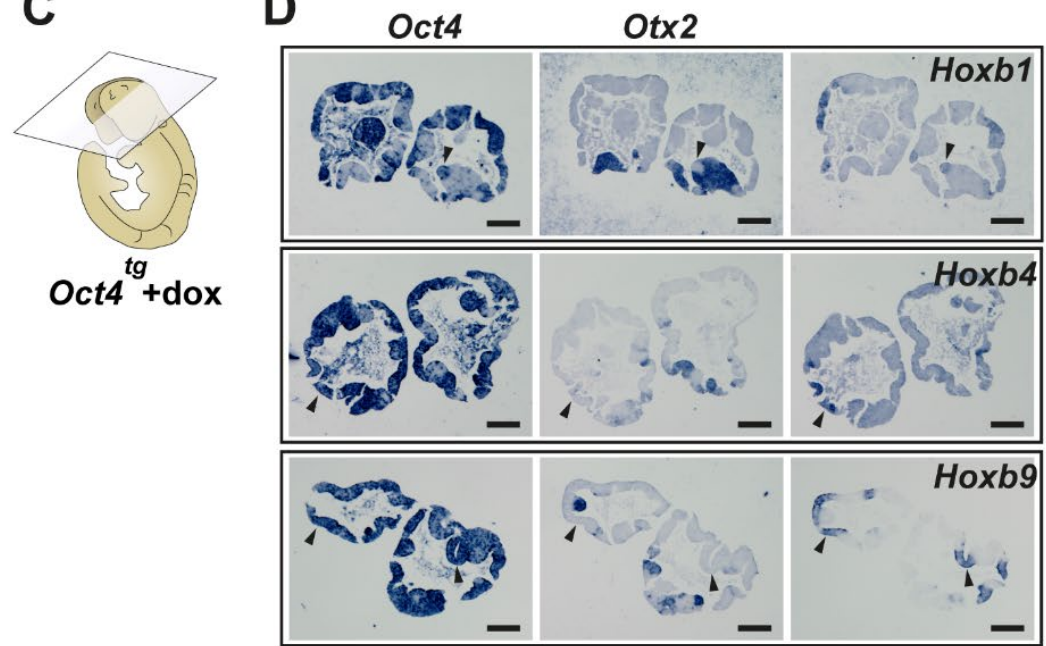

$\mathbf{E}$



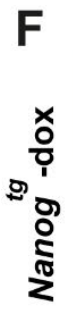

Hoxb9

Fig. S4. Changes to Hox gene expression patterns by pluripotency factors. $(A)$ Close-up views of E9.5 embryos show in Fig. 2D. The expression of Hoxb1 is expanded anteriorly (white arrowhead) in dox treated Oct4t ${ }^{\text {tg }}$ embryos and higher levels of expression are observed in presumptive rhombomere 6 (asterisk). Neural expression of Hoxb4 shows a patchy and disorganized pattern upon dox treatment (bracket) but no change in its anterior limit (white arrowhead). Neural expression of Hoxb9 is shifted anteriorly (white arrowhead) in relation to its limit of expression in the paraxial mesoderm (black arrowhead). Scale bar, $250 \mu \mathrm{m}$. (B) Highmagnification anterior views of HoxB gene expression in vesicle-like structures in the anterior neural tube of dox-treated Oct4tg embryos. Scale bar, $250 \mu \mathrm{m}$. (C) Diagram indicating the section plane of dox-treated Oct4tg embryos shown in $D$ and $E$. $(D)$ In situ hybridization on consecutive sections for Oct4 and Otx2 together with Hoxb1 (top), Hoxb4 (middle) or Hoxb9 (bottom); arrowheads indicate Oct4 expression domains that have lost Otx2 and gained Hox gene expression. Scale bars, $250 \mu \mathrm{m}$. (E) In situ hybridization on consecutive sections for Hoxb1, Hoxb4 and Hoxb9, showing their co-expression (arrows). Scale bars, $250 \mu \mathrm{m}$. $(F)$ Whole mount in situ hybridization of HoxB cluster gene expression in E9.5 controls (-dox, top row) and treated (+dox, bottom row) Nanog ${ }^{\text {tg }}$ embryos. White arrowheads indicates the anterior limit of expression of Hoxb1 in the neural tube. Scale bar, $250 \mu \mathrm{m}$. 
bioRxiv preprint doi: https://doi.org/10.1101/564658; this version posted March 5,2019 . The copyright holder for this preprint (which was not certified by peer review) is the author/funder, who has granted bioRxiv a license to display the preprint in perpetuity. It is made available under aCC-BY-NC 4.0 International license.

Dual regulation of Hox genes by pluripotency factors Lopez-Jimenez et al.
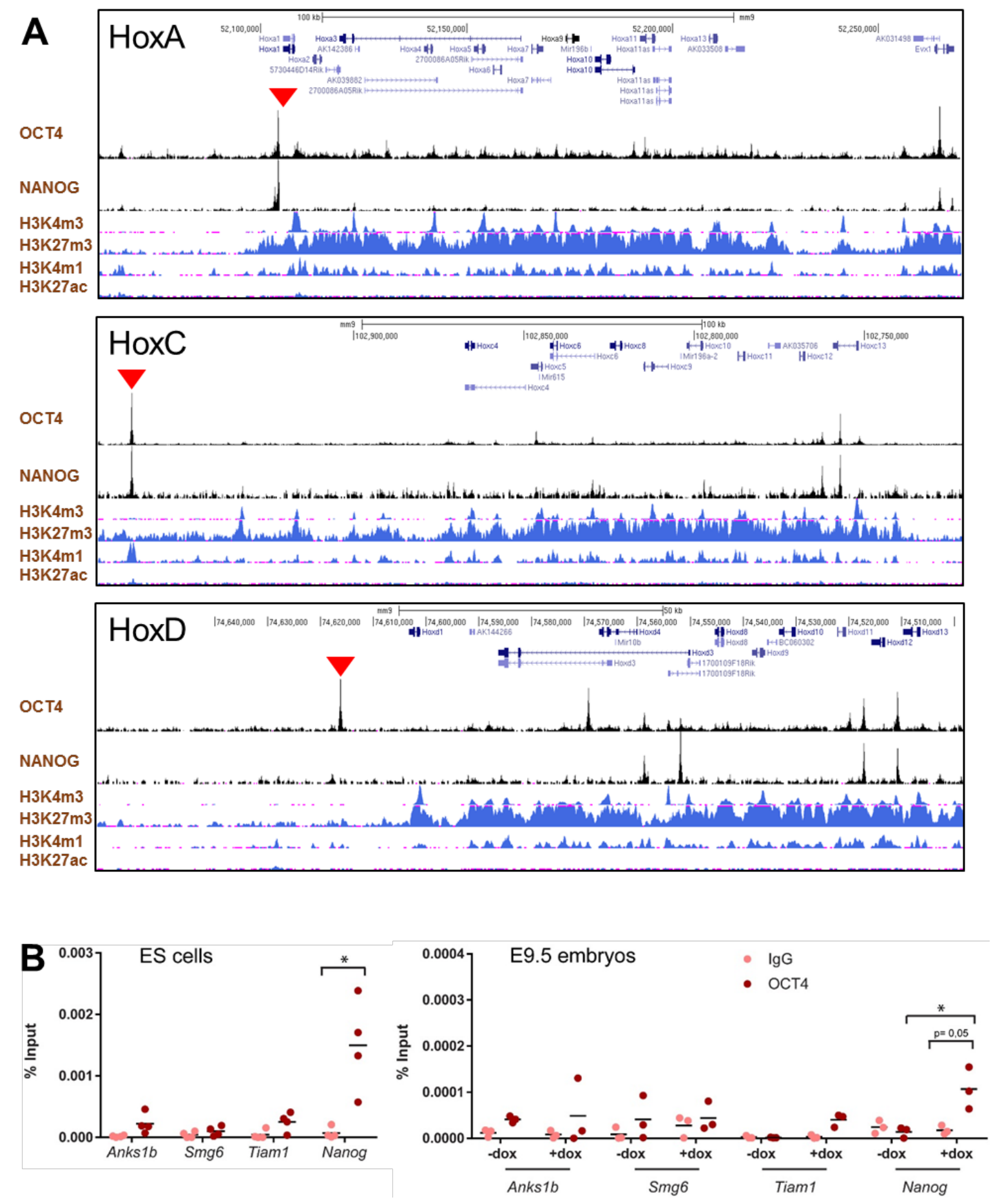
Fig. S5. (A) ChIP-seq binding profiles for OCT4 and NANOG (29) along HoxA (mm9; chr6:52,059,532-52,270,099), HoxC (mm9; chr15:102,720,415-102,975,124; reversed) and HoxD (mm9; chr2:74,498,129-74,662,259; reversed) clusters in ES cells. Distribution of histone marks for active transcription (H3K4m3), repression (H3K27m3) and active regulatory elements (H3K4m1, H3K27ac) in Bruce4 ES cells (58) is shown below. Red arrowheads indicate strong binding of pluripotency factors at the anterior end of the clusters. $(B)$ ChIP-qPCR of OCT4 binding to the positive (Nanog promoter) and negative (Anks1b, Smg6 and Tiam1) control regions in ES cells (left panel, $n=4$ ) and in untreated (-dox) and treated (+dox) E9.5 Oct4tg embryos (right panel, $\mathrm{n}=3$ ). Enrichment is shown as percentage of input for $\lg \mathrm{g}$ (negative control) and anti-OCT4 antibody. Horizontal bars indicate means. ${ }^{*} P$ value $<0.05$ by two-tailed Student $t$-test. 
bioRxiv preprint doi: https://doi.org/10.1101/564658; this version posted March 5, 2019. The copyright holder for this preprint (which was not certified by peer review) is the author/funder, who has granted bioRxiv a license to display the preprint in perpetuity. It is made available under aCC-BY-NC 4.0 International license.

Dual regulation of Hox genes by pluripotency factors

Lopez-Jimenez et al.

A

Oct4

Nanog

$C d x 2$
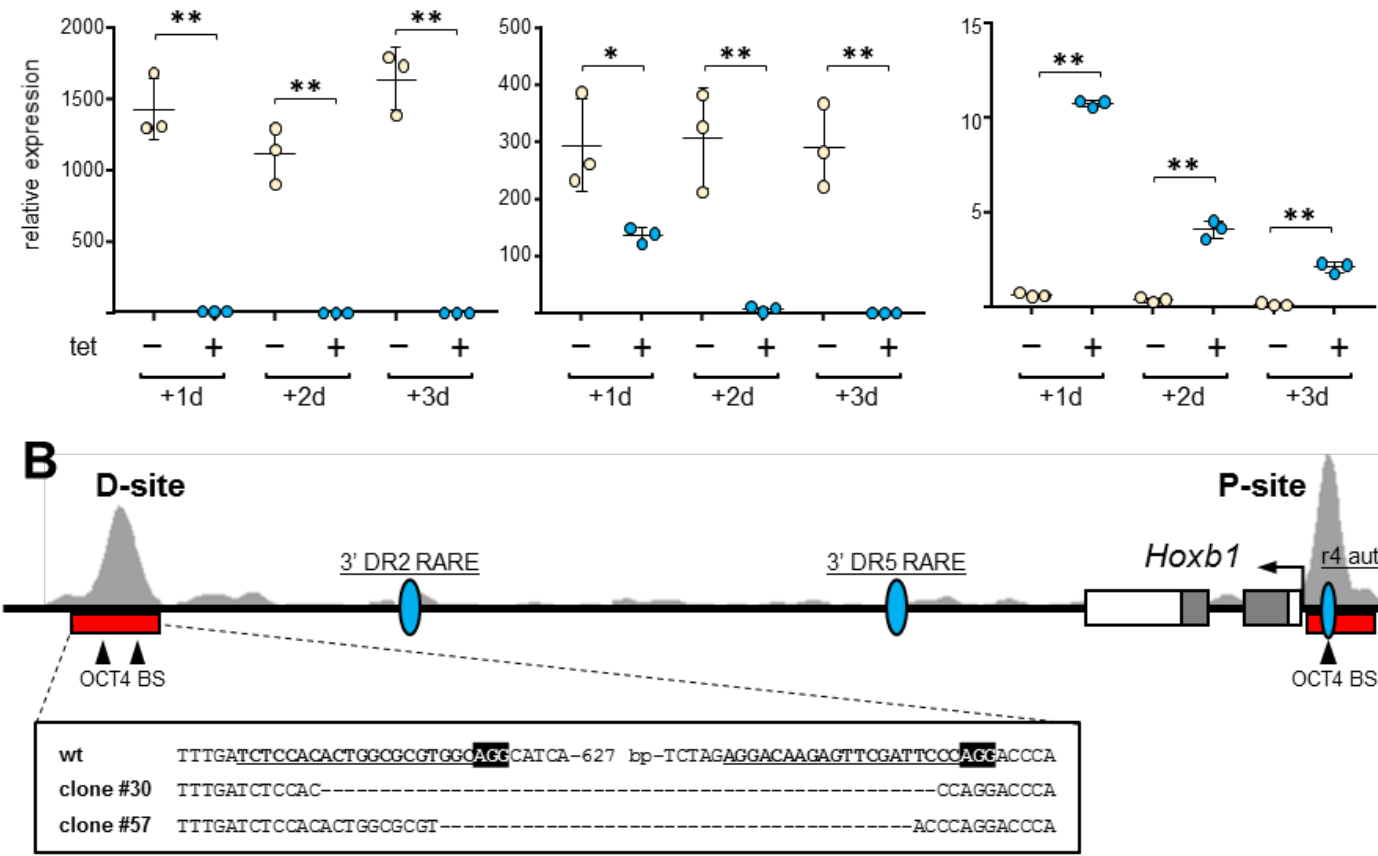

C

Tbx6

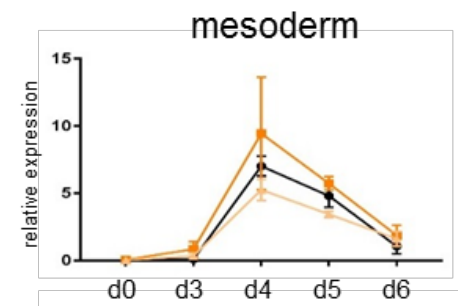

Pax6

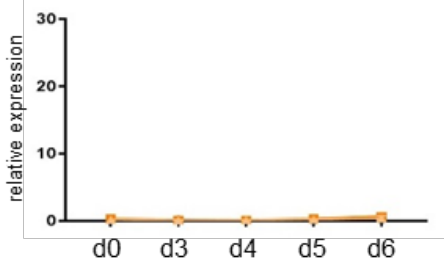





Hoxb4

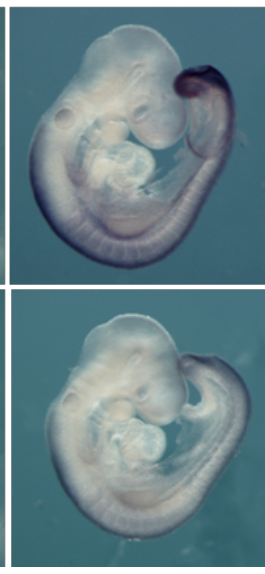

Hoxb9

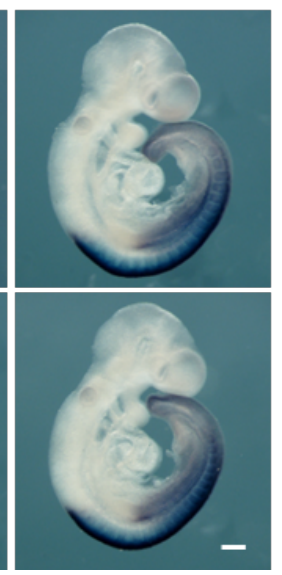

P-site

Hoxb1 4 r4auto

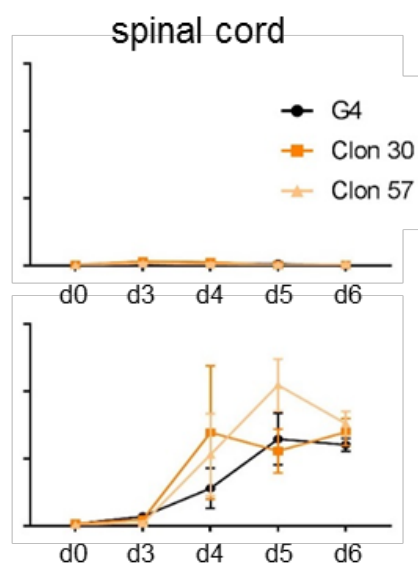

D

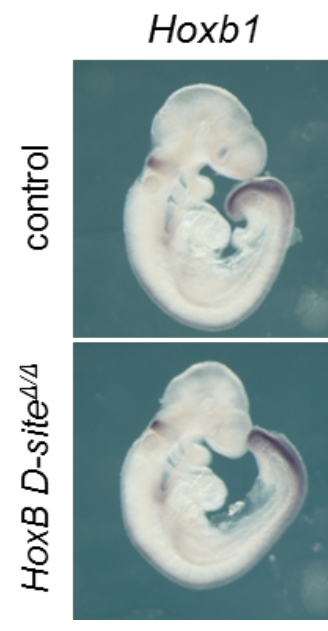


Fig. S6. Characterization of Oct4 depleted, and OCT4 D-site deleted ES cells and embryos. (A) Expression of Oct4, Nanog and $C d x 2$ as measured by RT-qPCR in untreated (-, pale yellow) and tetracycline (tet) treated (+, blue) ZHBTc4 ES cells for three days (d1-d3), what causes Oct4 downregulation. Statistical significance was calculated by Fisher's Least Significant Difference test; $P$ value: ${ }^{*}<0.05$, ${ }^{* *}<0.01$. (B) Genomic organization of the Hoxb1 locus (mm9; chr11:96226282-96237333). Exons are indicated by boxes and the position of the Hoxb1 promoter is indicated by an arrow. The location of distal $(D)$ and proximal $(P)$ binding sites is indicated by a red bar below ChIP-seq tracks for OCT4 (29) shown in light gray. The position of previously described regulatory elements for Hoxb1 (the r4 auto-regulatory element, r4 auto; and two retinoic acid response elements, 3' DR2 and 3' DR5) is indicated by blue ovals. Arrowheads show the positon of consensus OCT4 binding sites located within the $\mathrm{D}$ and $\mathrm{P}$ sites. Below (boxed) the sequences of the deleted clones generated by CRISPR/Cas9 editing are shown. gRNAs are underlined and in bold type, and the PAM is indicated in black background and bold white lettering in the wild type (wt) sequence. $(C)$ Expression as measured by RT-qPCR of a mesodermal (Tbx6) and a neural (Pax6) marker in control ES cells (G4, black line) and clones deleted for the distal OCT4 binding site (\#30, dark orange; \#57, light orange) during six days of differentiation along mesodermal, hindbrain, or spinal cord lineages. Expression is shown as relative levels. Error bars indicate $S D, \mathrm{n}=3$. $(D)$ Whole mount in situ hybridization for Hoxb1, Hoxb4 and Hoxb9 cluster in control (top row) and HoxB D-site ${ }^{\Delta / \Delta}$ (bottom row) E9.5 embryos. Scale bar, $250 \mu \mathrm{m}$. 